\title{
An Anecdote of Investor Anxiety and Momentum in China
}

\author{
Hung-Wen Lin, ${ }^{1}$ Kun-Ben Lin $\mathbb{D},{ }^{2}$ Jing-Bo Huang, ${ }^{3}$ and Xia-Ping Cao $\mathbb{D}^{4}$ \\ ${ }^{1}$ Business School, Nanfang College of Sun Yat-Sen University, Guangzhou, China \\ ${ }^{2}$ School of Business, Macau University of Science and Technology, Macau, China \\ ${ }^{3}$ Lingnan College, Sun Yat-Sen University, Guangzhou, China \\ ${ }^{4}$ College of Economics, Shenzhen University, Shenzhen, China \\ Correspondence should be addressed to Xia-Ping Cao; jerrycao76@qq.com
}

Received 6 December 2019; Revised 28 February 2020; Accepted 7 March 2020; Published 25 April 2020

Academic Editor: Dehua Shen

Copyright (c) 2020 Hung-Wen Lin et al. This is an open access article distributed under the Creative Commons Attribution License, which permits unrestricted use, distribution, and reproduction in any medium, provided the original work is properly cited.

\begin{abstract}
We show the effect of investor anxiety on momentum in the Chinese stock market. In this market dominated by retail investors, we examine the momentum profits in 900 types of daily testing periods. We find prevalent price reversals in the long formation and holding periods in the Chinese A-share market. Compared to Goyal and Wahal (2015), Wang and Xie (2010), and Kang et al. (2002) who found no momentum, our novel finding from a daily basis is that the A-share market presents price momentum within the short formation and holding periods. We first test the momentum profits under different strengths of anxiety in the A-share market. The stocks held by the least anxious investors elicit the strongest price momentum, whereas the stocks held by the most anxious investors encounter much weaker price momentum in the A-share market. According to our empirical outcomes, the A-share market overall exhibits higher anxiety and weaker momentum, whereas the B-share market embodies milder anxiety and stronger momentum. From the results of single market and cross-market comparisons, the intrinsic anxiety of retail investors is an essential factor stimulating the Chinese stock market to be prone to price reversals.
\end{abstract}

"Anxiety arises from a transformation of the accumulated tension."

\section{Sigmund Freud}

\section{Introduction}

This paper investigates the relationship between investor anxiety and momentum in the Chinese stock market. Anxiety is an issue that has long been a concern in both psychology and finance. Compared to professional institutional investors, retail investors find it more difficult to grasp the essence of information due to information asymmetries, so that they are very easy to embody anxiety. Consequently, we focus attention on digesting the effect of investor anxiety on momentum.

To the best of our knowledge, there has not been momentum research throwing light on the effect of investor anxiety. A series of studies dissect the effect of negative investor sentiment or disposable panic (e.g., [1-15]). Although their endeavors on these topics have deepened our insights into the stock market, they do not directly detect the effect of anxiety. Hence, we dedicate to the effect of intrinsic and continuous anxiety from retail investors. In addition, the strength of anxiety will influence the behaviors of retail investors, thus activating considerable impacts on the stock market.

The appearance of severe anxiety is possible to provoke the investors to be tense and thus arouses overreactions when facing information asymmetries and uncertainties. On the contrary, when anxiety is weak, there may be underreactions or delayed reactions (e.g., [16-18]). Price momentum and price reversal are two essential characteristics of the stock price. According to Jegadeesh and Titman [19], price momentum depicts a pattern whereby past trends in stock prices will be maintained and will continue into the 
future. This phenomenon originates from an underreaction or delayed reaction to firm-specific information. By contrast, price reversal implies that the past price trends of stocks will turn in opposite directions in the future, as the result of an overreaction to firm-specific information [20]. Hence, we would like to discuss how the changes in anxiety influence price momentum and reversal since these two characteristics of stocks come from underreaction and overreaction.

Psychologically, anxiety is a complex and mixed sentiment. When considered in more detail, anxiety is one type of negative sentiment regarding nervousness, tension, worry, and fear as faced by human beings (e.g., [21-25]). This type of sentiment will become a disorder once it persists for a period [26]. According to Peterson [27] and Passer and Smith [28], a panic disorder is one form of anxiety disorder that stems from terrifying attacks and that causes the agents to feel extremely tense. Therefore, we employ panic as a proxy for anxiety in this paper. To be precise, we use Lauterbach and Ben-Zion's [29] relative order imbalance (ROI) to represent the panic of investors, which is calculated on the basis of the standardized differences between the bid volume (BV) and ask volume (SV) (Spielberger [22] pointed out that anxiety is always accompanied by physiological arousal; bid volume and ask volume to some extent reflect investor trading behavior, whereby the relative order imbalance is a suitable proxy for anxiety given that it reflects the investor's panic).

China established its stock market in the 1990s and it grew rapidly, being comprised of the Shanghai stock exchange and Shenzhen stock exchange. However, the Chinese stock market is mainly characterized by violent price reversal rather than momentum (the stock markets in Europe and the US behave differently; in a one-month period, the stock markets exhibit a short-term price reversal; from two to twelve months, the stock markets are characterized by intermediate-term price momentum; moreover, in a three-tofive-year period, the markets tend to be trapped in a longterm price reversal (e.g., [30-33])). Under the dilemmas of high market volatilities and information asymmetries, the dominant retail investors may exhibit anxiety and thus overreactions, eliciting the emergence of reversal. In Figure 1 , we present reversal ratios in various periods. We calculate percentage of the stocks having opposite price trends between formation and holding periods to obtain reversal ratios (in the construction of momentum portfolios, we must select winner and loser stocks in the formation period and then calculate the momentum profits in the holding period; the formation period is the period in which we select stocks based on the price growth rate and the holding period is the period in which we acquire momentum profit in the future; winner stocks are those with the highest price growth rate and loser stocks have the lowest price growth rate; each pair of formation and holding periods results in a momentum portfolio; please see Section 2.2 for more details). Among 900 reversal ratios for various periods, most of the ratios range from $40 \%$ to $75 \%$, suggesting that at least $40 \%$ of stocks will reverse their past price trends in the future within a momentum portfolio. Even in the short formation and holding periods, there are still approximately

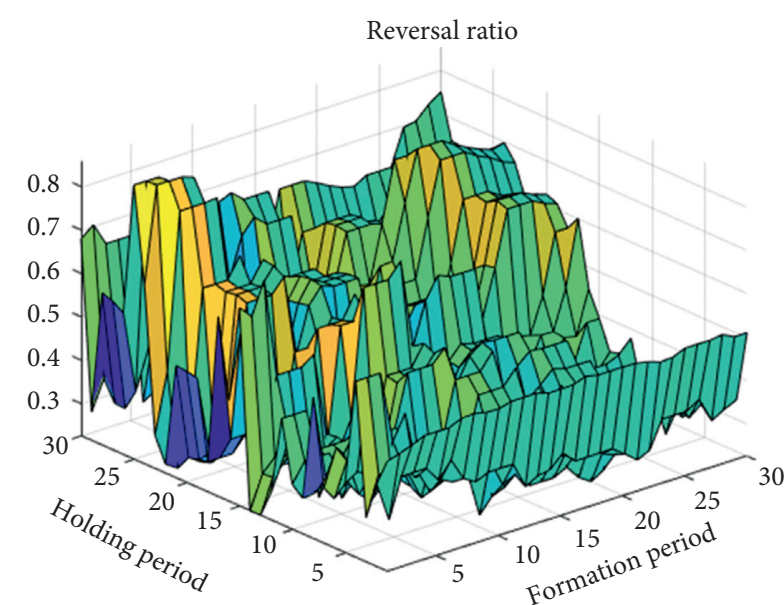

FIgURE 1: Daily reversal ratios in various periods. In the figure, the daily reversal ratios are plotted for various testing formation and holding periods. The maximum formation and holding periods are 30 days each, allowing 900 cases to come into being. We calculate the percentage of stocks that reverse their past price trends in the future. The reversal ratio is (\# (REVS)/\# (MOMS)), where \# (REVS) denotes the number of stocks reversing their prices and \# (MOMS) is the total number of stocks within a momentum portfolio.

half of stocks reversing their past price trends in the future. In the relatively long formation and holding periods, the reversal ratios all vary around $70 \%$. These outcomes indicate that the Chinese stock market is a particularly special market in the world, thereby implying that it is very important for us to understand its in-depth structure.

The empirical analysis involves the following steps. First of all, following the conventional vein in terms of the momentum, the preliminary dissection relies on the conditional momentum portfolio. All stocks in the market are initially classified into several groups based on investor anxiety and subsequently sorted by the price growth rate within the groups according to the anxiety classifications. Second, the capital asset pricing model [34-36], FamaFrench three-factor asset pricing model [37], and Chinese three-factor asset pricing model [38] come into their own to adjust the risks of momentum profits. Besides, we examine the momentum profits with different strengths of investor anxiety in the various testing periods.

What enables our study to stand out is that our momentum computations are based on a daily basis. If we make experiments on momentum profits in the Chinese stock market based on a monthly basis, it will be easy to find out significantly negative momentum profits, suggesting that price reversals prevail in the Chinese stock market (e.g., $[30,39-43])$. However, in an actual stock market, transactions take place every day, and so tests conducted using monthly data may fail to capture the stocks' real price movements. Hence, we perform examinations every day and generate the corresponding daily momentum profits to address the possible price momentum.

From a multidimensional perspective, the influencing mechanism of anxiety has been documented by previous studies. Gao et al. [44] and Kaplanski and Levy [45] have 
provided evidence that investor anxiety will negatively affect stock prices. Clearly, it is very likely that a great degree of anxiety will stimulate high fluctuations and dramatic declines in stock prices (e.g., [46-48]). In addition, Levy and Galili [49] hold that investors will engage in gambling activities in order to escape from the dilemma of anxiety. As for panic, due to it being one form of anxiety, it similarly exerts negative impacts on stock prices in the same manner (e.g., [50-52]). Based on the discussions above, anxiety is tightly related to stock price movements. Thus, it is reasonable for us to interpret how anxiety affects price momentum and reversal in China. The resulting findings will offer insights to both academia and industry.

We encode our story as follows. In the next section, the methodology and data descriptions in this paper are provided. Sections 3 and 4 report the empirical results of the A-share and B-share markets. The robustness checks are conducted in Section 5, and we conclude the paper in Section 6.

\section{Methodology and Data}

This section introduces the essence of investor anxiety, momentum profit, the conditional momentum portfolio, and asset pricing models used in this paper. We follow the approaches adopted by Jegadeesh and Titman [19] and Lauterbach and Ben-Zion [29] to measure momentum profit and investor anxiety, respectively. Consistent with past research on momentum, we derive the conditional momentum portfolio from a sequential classification. Furthermore, the capital asset pricing model, Chinese three-factor asset pricing model, and Fama-French three-factor asset pricing model are adopted to adjust risks.

2.1. Two Measures for Investor Anxiety. In psychology, anxiety consists of many negative sentiments, and thus it is difficult for us to construct a composite index for it. One possible way is to choose a proxy for a component of anxiety. Coon and Mitterer [53], Lahey et al. [24], and Peterson [54] all regard panic as one type of anxiety, and so panic is considered to be an appropriate representative of anxiety. According to Lauterbach and Ben-Zion [29], we measure the panic behavior based on a daily relative order imbalance. This variable implies instantaneous panic behavior on the part of investors.

$$
\mathrm{ROI}_{i, d}=\frac{\mathrm{BV}_{i, d}-\mathrm{SV}_{i, d}}{\left(\left(\sum_{d=1}^{D}\left|B V_{i, d}-S V_{i, d}\right|\right) / D\right)},
$$

where $\mathrm{ROI}_{i, d}$ is the daily relative order imbalance of stock $i$ on day $d, \mathrm{BV}$ is the bid volume, $\mathrm{SV}$ is the ask volume, and $D$ is the number of days in a period. According to Lauterbach and Ben-Zion [29], a lower value of $\mathrm{ROI}_{i, d}$ indicates that a stock faces higher selling pressure, suggesting more severe anxiety.

We have already mentioned that anxiety will become a disorder if it persists for a period in Section 1. The quote from Freud also indicates the importance of accumulation in anxiety (e.g., [55-57]). According to their conceptions, we set up a proxy for the accumulation in anxiety. Our measure is as follows. The percentage of the negative relative order imbalance suggests the number of days with exceedingly severe anxiety, while the percentage of positive relative order imbalance represents the number of days with slight anxiety. Hence, the difference between them exactly indicates the accumulation in anxiety (a similar example can be seen in [58]).

$$
\mathrm{ACCI}_{i, p}=\operatorname{neg}_{i, p} \%-\operatorname{pos}_{i, p} \%,
$$

where $\mathrm{ACCI}_{i, p}$ is the accumulative relative order imbalance, neg $_{i, p} \%$ denotes the percentage for the negative relative order imbalance in a period, and $\operatorname{pos}_{i, p} \%$ is the percentage for the positive relative order imbalance in the period. Note that a lower value of $\mathrm{ACCI}_{i, p}$ suggests a lower accumulation in terms of anxiety.

2.2. The General Algorithm of Momentum. Motivated by Jegadeesh and Titman [19], in what follows we describe a general model to calculate the momentum profit in various periods. In the field of momentum research, we must choose the formation and holding periods first, and so we let $F$ denote the formation period and $H$ the holding period. The formation period is the period in which we rank stocks based on the past price growth rate, and the holding period is the period for which we calculate the momentum profits in the future.

If we use different types of time length for the formation and holding periods, there will be different types of momentum portfolios according to the time length. Assuming that the length of the formation period ranges from 1 to $M$ and that of the holding period from 1 to $V$, every pair of formation and holding periods results in a momentum portfolio. Hence, there will be total of $M \times V$ cases of momentum portfolios.

In the first period $t_{1}$, we use $P_{i, G}=\left(P_{i, f}^{F}-P_{i, 1}^{F} / P_{i, 1}^{F}\right)$ for each stock $i$ to rank the stocks for the market as a whole, where $t_{1}=F_{1}+1, F_{1}$ is the length of the formation period, $P_{i, G}$ is the price growth rate of each stock, $P_{i, f}^{F}$ is the price in the last period of the formation period, and $P_{i, 1}^{F}$ is the price in the beginning period of the formation period.

The $(1 / Q)$ stocks with the highest price growth rates constitute the winner portfolio and another (1/Q) stocks with the lowest price growth rates form the loser portfolio. We create a long position for the winner portfolio and a short position for the loser portfolio, and so these positions constitute the first momentum portfolio. During the holding period $H_{1}$, we calculate the return spread between the winner and loser portfolios:

$$
R_{t_{1}}^{s}=\overline{R_{H_{1}}^{W}}-\overline{R_{H_{1}}^{L}},
$$

where $\overline{R_{H}^{W}}$ is the average return of the winner portfolio during holding period $H_{1}, \overline{R_{H_{1}}^{L}}$ is the average return of the loser portfolio during holding period $H_{1}, H_{1}=\left[\theta^{H_{1}, 1}, \theta^{H_{1}, h}\right]$, $\theta^{H_{1}, h}$ is the last period of $H_{1}, \theta^{H_{1}, 1}$ is the first period of $H_{1}$, and $\theta^{H_{1}, 1}$ is equal to $t_{1}+1 . H_{1}=\left[\theta^{H_{1}, 1}, \theta^{H_{1}, h}\right]$ means that $H_{1}$ extends from period $\theta^{H_{1}, 1}$ to period $\theta^{H_{1}, h}$. Note that the 
construction of the momentum portfolio is based on a rolling procedure.

Therefore, in the period $t_{2}\left(t_{2}=\left(t_{1}+1\right)\right)$, we proceed to use $P_{i, G}$ in $F_{2}$ to rank the stocks, where $F_{2}=\left[\theta^{F_{1}, 2},\left(\theta^{F_{1}, f}+1\right)\right], \theta^{F_{1}, 2}$ is the second period of $F_{1}$, and $\theta^{F_{1}, f}$ is the last period of $F_{1}$. In a similar vein to the above, $F_{2}=\left[\theta^{F_{1}, 2},\left(\theta^{F_{1}, f}+1\right)\right]$ suggests that $F_{2}$ ranges from period $\theta^{F_{1}, 2}$ to period $\theta^{F_{1}, f}+1$. During the holding period $H_{2}$, we calculate the return spread:

$$
R_{t_{2}}^{s}=\overline{R_{H_{2}}^{W}}-\overline{R_{H_{2}}^{L}},
$$

where $\overline{R_{H}^{W}}$ is the average return of the winner portfolio during holding period $\mathrm{H}_{2}, \overline{R_{H_{2}}^{L}}$ is the average return of the loser portfolio during holding period $\mathrm{H}_{2}, \mathrm{H}_{2}=$ $\left[\theta^{H_{1}, 2},\left(\theta^{H_{1}, h}+1\right)\right]$, and $\theta^{H_{1}, 2}$ is the second period of $H_{1}$.

After rolling $n$ times, in period $t_{n}\left(t_{n}=\left(t_{1}+(n-1)\right)\right)$, we acquire the momentum portfolio by means of $P_{i, G}$ in $F_{n}$, where $F_{n}=\left[\theta^{F_{n-1}, 2},\left(\theta^{F_{n-1}, f}+1\right)\right], \theta^{F_{n-1}, 2}$ is the second period of $F_{n-1}$, and $\theta^{F_{n-1}, f}$ is the last period of $F_{n-1}$. During $H_{n}$, the return spread is

$$
R_{t_{n}}^{s}=\overline{R_{H_{n}}^{W}}-\overline{R_{H_{n}}^{L}}
$$

where $\overline{R_{H_{n}}^{W}}$ is the average return of the winner portfolio during holding period $H_{n}, \overline{R_{H_{n}}^{L}}$ is the average return of the loser portfolio during holding period $H_{n}$, $H_{n}=\left[\theta^{H_{n-1}, 2},\left(\theta^{H_{n-1}, h}+1\right)\right], \theta^{H_{n-1}, 2}$ is the second period of $H_{n-1}$, and $\theta^{H_{n-1}, h}$ is the last period of $H_{n-1}$.

Finally, we have $n$ return spreads, so the momentum profit (MP) is

$$
\mathrm{MP}=\frac{1}{n} \sum_{q=1}^{n} R_{t_{q}}^{s} .
$$

In addition, the signs of the momentum profit tell two stories. When the momentum profit is significantly positive, the market exhibits price momentum, suggesting that past price trends will continue in the future. By contrast, the market is characterized by price reversal if the momentum profit is significantly negative. In other words, past price trends will reverse in the future.

2.3. Conditional Momentum Portfolio. The effect of investor anxiety on the momentum profit is dissected by the conditional momentum portfolio in this paper (e.g., [59-61]). To be concrete, in the formation period, all the stocks for the market as a whole are first classified by investor anxiety into several groups. Subsequently, within each group generated from the anxiety classifications, the stocks are further classified by the formation price growth rate to construct winner and loser portfolios. Moreover, the momentum profits under various degrees of anxiety are obtained from the return spreads between the winner and loser portfolios with the same degrees of anxiety. To see the details of the conditional momentum portfolio, please refer to Appendix A.

2.4. Asset Pricing Models. We implement three asset pricing models to perform the risk adjustments for the momentum profit. The models include the capital asset pricing model (CAPM), Chinese three-factor asset pricing model [38], and Fama-French three-factor asset pricing model [37].

$$
\begin{aligned}
& \mathrm{WML}_{j, t}=\alpha_{j}+\beta_{j} \mathrm{MKT}_{t}+\varepsilon_{j, t}, \\
& \mathrm{WML}_{j, t}=\alpha_{j}+\beta_{j} \mathrm{MKT}_{t}+\sum_{z=1}^{2} \delta_{z, j} \mathrm{PF}_{z, t}^{\mathrm{CH}}+\varepsilon_{j, t}, \\
& \mathrm{WML}_{j, t}=\alpha_{j}+\beta_{j} \mathrm{MKT}_{t}+\sum_{z=1}^{2} \lambda_{z, j} \mathrm{PF}_{z, t}^{\mathrm{FF}}+\varepsilon_{j, t},
\end{aligned}
$$

where $\mathrm{WML}_{j, t}$ is the winner-minus-loser return spread under different degrees of investor anxiety, $\mathrm{MKT}_{t}$ is the market risk pricing factor of the CAPM, and $\mathrm{PF}_{z, t}^{\mathrm{CH}}$ represents the size and value pricing factors from Liu et al. [38]. In addition, $\mathrm{PF}_{z, t}^{\mathrm{FF}}$ denotes the size and value pricing factors obtained from Fama and French [37]. Following Celiker et al. [62], Chen and Zhao [63], and Garlappi and Yan [64], we utilize the regression intercepts of these models as riskadjusted momentum profits. Appendix B shows the construction procedures of these pricing factors.

2.5. Data Descriptions. All the data in this paper are obtained from the China Stock Market and Accounting Research (CSMAR) database. The sample period ranges from the year 2007 to the year 2018 and encompasses both $\mathrm{A}$-share and B-share stocks in China. To obtain the value pricing factor as in [38], we first compute the earnings-toprice ratio of each stock. Earnings is measured as net profit in excess of nonrecurrent gains and losses. As nonrecurrent gains and losses begin in the year 2007, we thus select this sample. Table 1 provides the descriptive statistics for the daily relative order imbalance and accumulative relative order imbalance of the A-share and B-share markets.

From Table 1, we can observe the mean values of daily relative order imbalance (ROI) and accumulative relative order imbalance (ACCI) for both A-share and B-share markets. The B-share market has a mean value in ROI of 0.2376 , while the A-share market has a mean value in ROI of 0.1115 , suggesting that A-share market has higher instantaneous anxiety than the B-share market. In addition, the A-share market acquires an ACCI of -0.0433, which is higher than that of the B-share market (B-share market has an ACCI of -0.1715), again implying that A-share market has higher anxiety from the perspective of accumulative relative order imbalance.

\section{Empirical Results of the A-Share Market}

This section examines how investor anxiety affects momentum profits through different avenues. First, we show the momentum profits of the A-share market as a whole in various periods. We then present the results for the 1-day, 2day, 3-day, 30-day, and 180-day periods under different strengths of anxiety. Third, the outcomes for the extended periods under different strengths of anxiety are also depicted by several 3D figures. 
TABle 1: Descriptive statistics.

\begin{tabular}{lcc}
\hline Mean & A-share market & B-share market \\
\hline ROI & 0.1115 & 0.2376 \\
ACCI & -0.0433 & -0.1715 \\
\hline
\end{tabular}

This table presents the mean value of daily relative order imbalance (ROI) and accumulative relative order imbalance (ACCI) for the market as a whole. They are obtained based on a daily basis.

3.1. Momentum Profits of the A-Share Market in Various Periods. In this section, we draw a figure for the momentum profits of the A-share market as a whole. The formation and holding periods of momentum portfolios respectively range from 1 day to 30 days. Figure 2 shows the results.

From Figure 2, we can observe that most of the momentum profits from the A-share market are below 0 and related absolute $t$-statistics are all higher than 1.96. Although there are also significantly positive momentum profits, they just occur in the very short run. To be concrete, within 10 days, there are evident price momentum, but the results all turn to be price reversals if the periods are over 10 days. These outcomes show that the Chinese A-share market mainly embodies price reversals in most of the periods we adopt but presents price momentum in the very short run.

3.2. Investor Anxiety and Momentum Profits of the A-Share Market. In this section, we study how the daily relative order imbalance and accumulative relative order imbalance affect the daily momentum profits. Table 2 reports the effect of the daily relative order imbalance, while that of the accumulative relative order imbalance takes shape in Table 3.

\subsubsection{Daily Relative Order Imbalance: Baseline Results.} We dissect the effects of the daily relative order imbalance among Chinese A-share stocks. Table 2 presents the daily momentum profits and corresponding $t$-statistics for different levels of the daily relative order imbalance, which emphasizes the impact of instantaneous anxiety.

From Table 2, for the very short run of Panel A, we can see that the highest level of the daily relative order imbalance induces the most significantly positive momentum profit (the $t$-statistic is 24.2763) for the 1-day period. When we enter the 2-day and 3-day periods, this result is maintained. That is, the highest daily relative order imbalance still gives rise to the most significantly positive momentum profits (the $t$-statistics are 13.0337 and 8.9987 , respectively). The highest daily relative order imbalance means that the stocks face the lowest selling pressure, implying the lowest instantaneous anxiety. This outcome suggests that the lowest instantaneous anxiety elicits the strongest price momentum in the very short run.

However, when we enter the 30-day and 180-day periods, we find that the result turns in a totally opposite direction. For the 30-day period, the discovery is that the highest daily relative order imbalance leads to the most significantly negative momentum profit with an absolute $t$ statistic of over 19, while the lowest daily relative order imbalance leads to the least significantly negative momentum profit and the absolute $t$-statistic is greater than 13 . Moreover, in the case of the 180-day period, the highest daily relative order imbalance stocks still have the most significantly negative momentum profit with an absolute $t$-statistic of over 17, but the lowest one has a significantly negative momentum profit and the related absolute $t$-statistic is 10.7622. The results discussed above tell us that the lowest instantaneous anxiety gives rise to the most severe price reversal and the highest instantaneous anxiety activates the mildest price reversal in the long run.

Moreover, among Panels A, B, C, D, and E, there are significant differences in the momentum profits between the highest daily relative order imbalance group and the lowest daily relative order imbalance group since related absolute $t$ statistics are all over 5 . We compute $F$-statistics to examine whether the changes in daily relative order imbalance significantly influence the momentum profits (average winnerminus-loser return spreads). The results show that the winner-minus-loser return spreads from various groups do not have the same mean values ( $p$ values are all smaller than $5 \%$ ), suggesting that variations of daily relative order imbalance strongly affect momentum profits.

\subsubsection{Accumulative Relative Order Imbalance: Baseline} Results. Freud's quote shows the importance of accumulation in anxiety, and so we construct the accumulative relative order imbalance (ACCI) to study the accumulation of anxiety. In Table 3, we report the momentum profits and $t$-statistics among Chinese A-share stocks for different levels of the accumulative relative order imbalance.

In Table 3, we can find in the very short run for 1 day that the lowest accumulative anxiety (lowest ACCI) elicits the most significantly positive momentum profit (the $t$-statistic is 16.6676). This finding remains for the 2-day and 3-day period as the $t$-statistics are, respectively, 7.3361 and 4.8114 for the lowest accumulative anxiety stocks. Therefore, the lowest accumulative anxiety gives rise to the strongest price momentum in the very short run.

For the 30-day and 180-day periods, the phenomenon becomes wholly different. In Panel D and Panel E, the lowest accumulative anxiety stocks have the most significantly negative momentum profits because the absolute $t$-statistics are 20.4242 and 20.7767, respectively. Besides, the highest accumulative anxiety (highest ACCI) stocks result in the least significantly negative momentum profits with absolute $t$-statistics ranging from 7 to 8 . These discoveries document that the lowest accumulative anxiety stocks are trapped in the most severe price reversal and the highest accumulative anxiety stocks suffer from much milder price reversal than the lowest one in the long run.

In addition, we perceive that significant differences in momentum profits (average winner-minus-loser return spreads) occur between the highest and lowest ACCI groups as absolute $t$-statistics are higher than 2 from Panels $\mathrm{A}, \mathrm{B}, \mathrm{C}, \mathrm{D}$, and $\mathrm{E}$. We continue to use $F$-statistics to detect whether the winner-minus-loser return spreads from various groups grasp the same mean values. The outcomes 


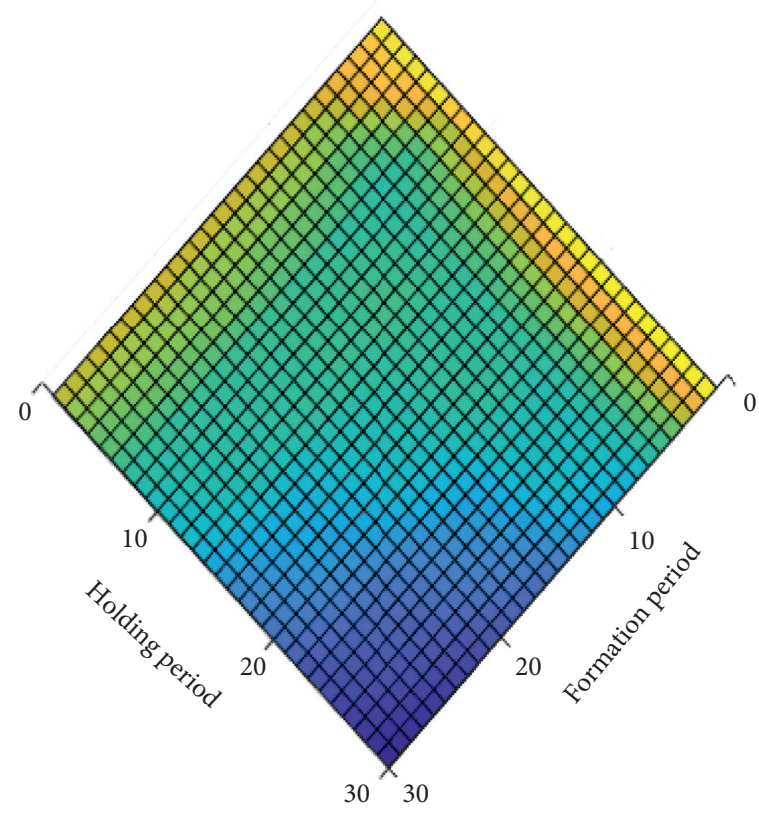

(a)

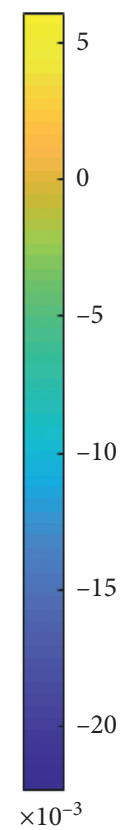

$\times 10^{-3}$

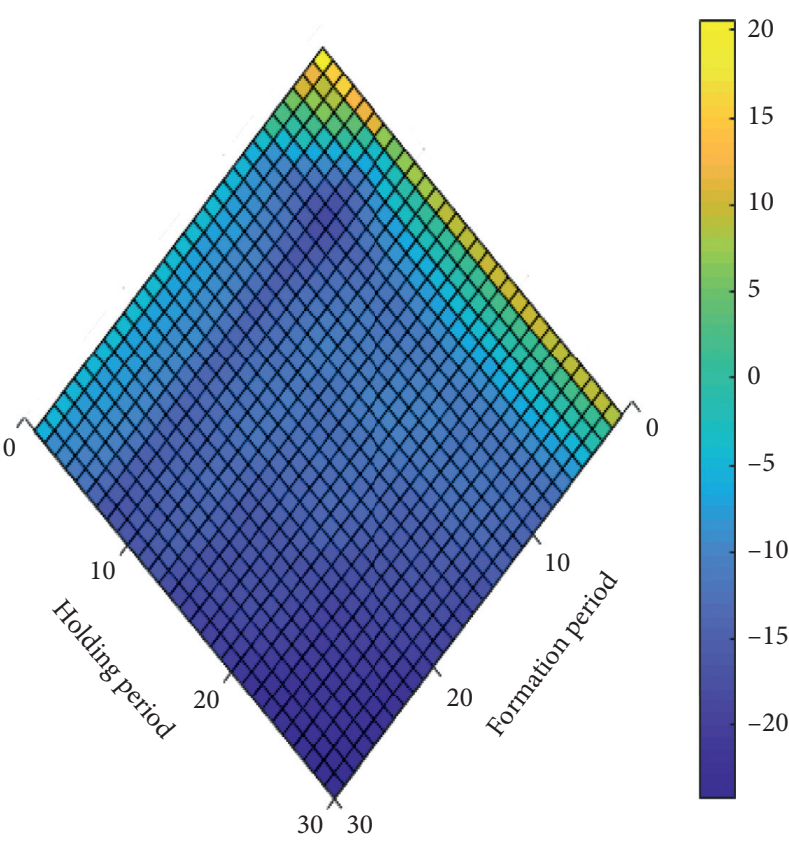

(b)

FIgURE 2: Momentum profits of the A-share market as a whole. This figure plots the momentum profits and related $t$-statistics of the A-share market in various periods. The formation and holding periods, respectively, range from 1 day to 30 days. (a) Momentum profit and (b) $t$ statistics.

document that the winner-minus-loser return spreads do not have the same mean values because the $p$ values of $F$ statistics are all below $5 \%$, implying that the changes in accumulative relative order imbalance significantly influence momentum profits.

3.2.3. Implications from the Baseline Results. In view of the instantaneous anxiety or accumulative anxiety, the empirical results are basically consistent with each other. In the very short run, the stocks held by the least anxious investors encounter the greatest price momentum, while the stocks held by the most anxious investors induce much weaker price momentum. However, in the relatively long run, the results change dramatically. That is, we all perceive strong price reversals regardless of the strength of anxiety.

The most intriguing point concerns why the lowest degree of anxiety behaves differently in the very short run and long run. With regard to the first, the lowest anxiety denotes extreme optimism. The majority of investors in the Chinese stock market are retail investors. This type of investor lacks sufficient knowledge and a decent information source compared to the institutional investors. The retail investors generally fail to make good decisions.

Our insights include that once the investors with poor decision making are characterized by extreme optimism, the stocks will be initially mispriced, but mispricing will be eventually corrected in the future. In the very short run, the retail investors do not have sufficient time to update their information. Due to their extreme optimism, they will not make any adjustments to their investments and will exhibit underreactions to information, exacerbating the price momentum of the stocks in which they invest. However, as time passes, the deviations from the fundamentals will not persist, suggesting that a price correction will finally come into being and a strong price reversal will also occur.

3.3. Risk Adjustments Using Asset Pricing Models of the A-Share Market. Section 3.2 reports the results of the baseline tests for anxiety and the momentum profits. In regard to momentum research, some may doubt whether the results are sufficiently robust after adjustments for risk using the asset pricing models. Hence, we answer this question below using the capital asset pricing model, Chinese threefactor asset pricing model [38], and Fama-French threefactor asset pricing model [37].

3.3.1. Daily Relative Order Imbalance: Risk Adjustments. Table 4 presents the outcomes of the risk adjustments for the momentum profits under different levels of instantaneous anxiety (represented by the daily relative order imbalance). From Table 4, after adjusting for the risks, the effect of instantaneous anxiety actually remains. In Panel A for the 1-day period, we can see that the lowest instantaneous anxiety (highest daily relative order imbalance) still generates the most significantly positive risk-adjusted momentum profits with $t$-statistics ranging from 23 to 23.2604 in spite of the asset pricing model's specifications. When we consider the 2-day and 3-day periods, the risk-adjusted momentum profits arising from the lowest instantaneous anxiety are also the most significantly positive (the $t$-statistics are over 12 and 8 , respectively). 
TABLE 2: The effect of the daily relative order imbalance of the A-share market.

\begin{tabular}{|c|c|c|c|c|c|}
\hline \multicolumn{6}{|c|}{ Panel A: $F=H=1$ day } \\
\hline ROI & Highest & 2 & 3 & 4 & Lowest \\
\hline MP & 0.0093 & 0.0033 & 0.0015 & 0.0020 & 0.0041 \\
\hline$t$-stat & 24.2763 & 10.7031 & 5.3008 & 7.3498 & 13.9771 \\
\hline & & & & 0.0052 & \\
\hline & & & & 11.1713 & \\
\hline & & & & 99.0568 & \\
\hline & & & & 0.0000 & \\
\hline \multicolumn{6}{|c|}{ Panel B: $F=H=2$ days } \\
\hline ROI & Highest & 2 & 3 & 4 & Lowest \\
\hline MP & 0.0064 & 0.0015 & 0.0009 & 0.0002 & 0.0022 \\
\hline \multirow[t]{5}{*}{$t$-stat } & 13.0337 & 3.8611 & 2.4428 & 0.4907 & 5.8371 \\
\hline & & & & 0.0042 & \\
\hline & & & & 8.0401 & \\
\hline & & & & 36.3640 & \\
\hline & & & & 0.0000 & \\
\hline \multicolumn{6}{|c|}{ Panel C: $F=H=3$ days } \\
\hline ROI & Highest & 2 & 3 & 4 & Lowest \\
\hline MP & 0.0051 & 0.0015 & 0.0009 & 0.0001 & 0.0018 \\
\hline \multirow[t]{5}{*}{$t$-stat } & 8.9987 & 3.1393 & 2.0881 & 0.2383 & 4.1545 \\
\hline & & & & 0.0033 & \\
\hline & & & & 5.862 & \\
\hline & & & & 17.8774 & \\
\hline & & & & 0.0000 & \\
\hline \multicolumn{6}{|c|}{ Panel D: $F=H=30$ days } \\
\hline ROI & Highest & 2 & 3 & 4 & Lowest \\
\hline MP & -0.0283 & -0.0248 & -0.0227 & -0.0213 & -0.0179 \\
\hline$t$-stat & -19.6921 & -18.2659 & -17.4103 & -16.3441 & -13.4833 \\
\hline & & & & -0.0104 & \\
\hline & & & & -6.2509 & \\
\hline & & & & 6.0864 & \\
\hline & & & & 0.0001 & \\
\hline \multicolumn{6}{|c|}{ Panel E: $F=H=180$ days } \\
\hline ROI & Highest & 2 & 3 & 4 & Lowest \\
\hline MP & -0.0529 & -0.0485 & -0.0438 & -0.0413 & -0.0307 \\
\hline \multirow[t]{5}{*}{$t$-stat } & -17.4868 & -16.5624 & -14.8212 & -14.2393 & -10.7622 \\
\hline & & & & -0.0222 & \\
\hline & & & & -6.9754 & \\
\hline & & & & 8.8145 & \\
\hline & & & & 0.0000 & \\
\hline
\end{tabular}

This table presents the daily momentum profits (MP) and related $t$-statistics ( $t$-stat) of A-share stocks. $F$ and $H$ represent the length of the formation and holding periods, respectively. For each day, we calculate the daily relative order imbalance (ROI) of every stock and sort the stocks according to the daily relative order imbalance for that day. Within each group based on previous sorts, we select winner and loser stocks based on the past price growth rate in the formation period and then calculate the momentum profit (average winner-minus-loser return spread) for the holding period. In addition, we also calculate the momentum profit (average winner-minus-loser return spread) of the highest-minus-lowest ROI (H-L) group. According to Montgomery [65], our analyses for the effects of ROI on momentum profits are single-factor experiments (SFE), so we calculate $F$-statistics to test if the winner-minus-loser return spreads from different groups have the same average values. We first test the momentum profits in the very short run. The most natural choice is 1 day, and we also calculate momentum profits for 2 days and 3 days for robustness. In addition, we further test the momentum profits for 30 days and 180 days to see how they behave in the relatively long run. The sorts conducted for the daily relative order imbalance (ROI) are divided into 5 groups. Winner stocks are the onefifth of stocks with the highest price growth rate, while loser stocks are the one-fifth of stocks with the lowest price growth rate. The formation and holding periods have the same length according to Verardo [66], Avramov et al. [67], and Hillert et al. [31]. The critical value of 5\% significance of $t$-statistic is 1.96 .

By throwing light on the 30-day and 180-day periods, the lowest instantaneous anxiety still induces the most significantly negative risk-adjusted momentum profits with absolute $t$-statistics of over 19 and 16 , respectively. In addition, the highest instantaneous anxiety (lowest daily relative order imbalance) generates the least significantly negative riskadjusted momentum profits as the absolute $t$-statistics only range from 9.9843 to 14.2392 . Therefore, the effect of instantaneous anxiety is not sensitive to the pricing risks.

3.3.2. Accumulative Relative Order Imbalance: Risk Adjustments. In Table 5, we show the results for accumulative anxiety after adjusting for risk. Similar patterns appear 
TABLE 3: The effect of the accumulative relative order imbalance of the A-share market.

\begin{tabular}{lccccc}
\hline \multicolumn{5}{c}{ Panel A: $F=H=1$ day } \\
ACCI & Highest & 2 & 3 & 4 & Lowest \\
\hline MP & 0.0026 & 0.0029 & 0.0028 & 0.0037 & 0.0066 \\
$t$-stat & 9.3112 & 9.4786 & 8.5720 & 10.6619 & 16.6676 \\
& & MP $(H-L)$ & & -0.004 & \\
& & $t$-stat & & -9.8863 & \\
& $F$-stat (SFE) & & 23.3471 & \\
& $p$ value & & 0.0000 & \\
\hline
\end{tabular}

\begin{tabular}{lccccc}
\hline \multicolumn{5}{c}{ Panel B: $F=H=2$ days } \\
ACCI & Highest & 2 & 3 & 4 & Lowest \\
\hline MP & 0.0013 & 0.0017 & 0.0010 & 0.0010 & 0.0037 \\
$t$-stat & 3.4724 & 4.4059 & 2.4176 & 2.3579 & 7.3361 \\
& MP $(H-L)$ & & -0.0024 & \\
& $\quad t$-stat & & -4.662 & \\
& $F$-stat (SFE) & & 7.0371 & \\
& $p$ value & & 0.0000 & \\
\hline
\end{tabular}

\begin{tabular}{|c|c|c|c|c|c|}
\hline \multicolumn{6}{|c|}{ Panel C: $F=H=3$ days } \\
\hline ACCI & Highest & 2 & 3 & 4 & Lowest \\
\hline MP & 0.0012 & 0.0017 & 0.0013 & 0.0003 & 0.0028 \\
\hline$t$-stat & 2.7862 & 3.8181 & 2.7958 & 0.5068 & 4.8114 \\
\hline \multicolumn{4}{|c|}{$\mathrm{MP}(H-L)$} & \multicolumn{2}{|l|}{-0.0016} \\
\hline & \multicolumn{2}{|c|}{$t$-stat } & & \multicolumn{2}{|l|}{-2.6848} \\
\hline & \multicolumn{2}{|c|}{$F$-stat (SFE) } & & \multicolumn{2}{|l|}{3.6393} \\
\hline & \multicolumn{2}{|c|}{$p$ value } & & \multicolumn{2}{|l|}{0.0057} \\
\hline \multicolumn{6}{|c|}{ Panel D: $F=H=30$ days } \\
\hline ACCI & Highest & 2 & 3 & 4 & Lowest \\
\hline MP & -0.0107 & -0.0169 & -0.0193 & -0.0248 & -0.0304 \\
\hline$t$-stat & -8.3662 & -12.1924 & -14.5438 & -18.2731 & -20.4242 \\
\hline & \multicolumn{2}{|c|}{$\mathrm{MP}(H-L)$} & \multicolumn{3}{|c|}{0.0197} \\
\hline & \multicolumn{2}{|c|}{$t$-stat } & \multicolumn{3}{|c|}{12.2662} \\
\hline & \multicolumn{2}{|c|}{$F$-stat (SFE) } & \multicolumn{3}{|c|}{29.5456} \\
\hline & \multicolumn{2}{|c|}{$p$ value } & \multicolumn{3}{|c|}{0.0000} \\
\hline \multicolumn{6}{|c|}{ Panel E: $F=H=180$ days } \\
\hline ACCI & Highest & 2 & 3 & 4 & Lowest \\
\hline MP & -0.0222 & -0.0281 & -0.0310 & -0.0484 & -0.0682 \\
\hline$t$-stat & -7.6851 & -8.9120 & -10.6797 & -16.4591 & -20.7767 \\
\hline & \multicolumn{2}{|c|}{$\mathrm{MP}(H-L)$} & \multicolumn{3}{|c|}{0.046} \\
\hline & \multicolumn{2}{|c|}{$t$-stat } & \multicolumn{3}{|c|}{13.1039} \\
\hline & \multicolumn{2}{|c|}{$F$-stat (SFE) } & \multicolumn{3}{|c|}{38.5732} \\
\hline & \multicolumn{2}{|c|}{$p$ value } & \multicolumn{3}{|c|}{0.0000} \\
\hline
\end{tabular}

This table presents the daily momentum profits (MP) and related $t$-statistics $(t$ stat) for A-share stocks. $F$ and $H$ represent the length of formation and holding periods, respectively. For each day, the accumulative relative order imbalance (ACCI $=$ neg\% - pos\%) for every stock is acquired for the formation period and we initially classify the stocks based on ACCI. Then, for each group based on previous classifications, the stocks are sorted according to the past price growth rate in the formation period to identify the winner and loser stocks. Momentum profits (based on the average winner-minus-loser return spread) are thus calculated for the holding period. We also calculate the momentum profit (average winner-minus-loser return spread) of the highest-minus-lowest ACCI (H-L) group. According to Montgomery [65], our analyses for the effects of ACCI on momentum profits are single-factor experiments (SFE), so we calculate $F$-statistics to test if the winner-minus-loser return spreads from different groups have the same average values. We first test for the momentum profits in the very short run. The most natural choice is 1 day, and we also calculate momentum profits for 2 days and 3 days for robustness. In addition, we further test the momentum profits for 30 days and 180 days to see how they behave in the relatively long run. The sorts on ACCI are categorized into 5 groups. Winner stocks are those for the one-fifth of stocks with the highest price growth rate, while loser stocks are those for the one-fifth of stocks with the lowest price growth rate. The formation and holding periods have the same length according to Verardo [66], Avramov et al. [67], and Hillert et al. [31]. The critical value of 5\% significance of $t$-statistic is 1.96 . once again. From Panel A, the risk-adjusted momentum profits are most significantly positive for the lowest accumulative anxiety (lowest ACCI) for the 1-day period ( $t$ statistics are over 15). Moreover, for the 2-day and 3-day periods, the lowest accumulative anxiety is still characterized by the strongest significantly positive momentum profits due to the $t$-statistics varying from 4.4912 to 6.9145 .

For the relatively long periods of 30 days and 180 days, the lowest accumulative anxiety produces the most significantly negative momentum profits owing to the absolute $t$ statistics all being over 19, but the highest accumulative anxiety (highest ACCI) results in the least significantly negative momentum profits (with the absolute $t$-statistics only varying from 6.6017 to 9.0809 ). Hence, the effect of accumulative anxiety is also not sensitive to the pricing risks.

3.4. Extended Periods of the A-Share Market. We further extend the formation and holding periods of the momentum profits in this section so that we can build up a clearer pattern of the effect of anxiety.

3.4.1. Daily Relative Order Imbalance in Extensions of the A-Share Market. The effects of the highest daily relative order imbalance and lowest daily relative order imbalance are studied in extensions. We depict the momentum profits and $t$-statistics in Figures 3 and 4.

Figure 3 shows that the momentum profits vary from -0.03 to 0.01 and large part of the surface of momentum profit is below 0 . The daily momentum profits are only significantly positive in the very short run under the lowest instantaneous anxiety (highest daily relative order imbalance) because the $t$-statistics are all greater than 10 or even over 20. However, the results become significantly negative once the testing periods are extended (most of the absolute $t$ statistics are close to 10 or even equal to 20). These outcomes again document that the lowest instantaneous anxiety only produces price momentum in the short run but leads to severe price reversal in the long run.

While Figure 4 appears to be similar to Figure 3, there are obvious distinctions between the two. In Figure 4, most of momentum profits are also smaller than 0 . The $t$-statistics of the significantly positive momentum profits under the highest instantaneous anxiety (lowest daily relative order imbalance) only change around 10 in the very short run. In the long run, although the highest instantaneous anxiety also induces significantly negative momentum profits, most of the absolute $t$ statistics only vary from 2.5 to 10 . By contrast, many absolute $t$-statistics in Figure 3 change around 20. The absolute momentum profits in Figure 4 range from 0.004 to 0.02, but those in Figure 3 lie between 0.01 and 0.03, suggesting that the impacts of the lowest instantaneous anxiety on price momentum or reversal are always stronger than those for the highest instantaneous anxiety in extended periods.

3.4.2. Accumulative Relative Order Imbalance in Extensions of the A-Share Market. We examine the effects of the highest accumulative relative order imbalance and lowest accumulative 
TABLE 4: The effect of the daily relative order imbalance after risk adjustments of the A-share market.

\begin{tabular}{|c|c|c|c|c|c|}
\hline \multicolumn{6}{|c|}{ Panel A: $F=H=1$ day } \\
\hline ROI & Highest & 2 & 3 & 4 & Lowest \\
\hline 1F alpha & 0.0090 & 0.0030 & 0.0014 & 0.0019 & 0.0041 \\
\hline$t$-stat & 23.2604 & 9.8018 & 5.0059 & 6.7069 & 13.7079 \\
\hline $\mathrm{CH}-3$ alpha & 0.0090 & 0.0030 & 0.0014 & 0.0018 & 0.0041 \\
\hline$t$-stat & 23.1289 & 9.7904 & 4.9579 & 6.6669 & 13.6641 \\
\hline FF-3 alpha & 0.0090 & 0.0030 & 0.0014 & 0.0019 & 0.0042 \\
\hline$t$-stat & 23.0065 & 9.7215 & 4.9283 & 6.6714 & 13.6330 \\
\hline \multicolumn{6}{|c|}{ Panel B: $F=H=2$ days } \\
\hline ROI & Highest & 2 & 3 & 4 & Lowest \\
\hline $1 \mathrm{~F}$ alpha & 0.0063 & 0.0014 & 0.0010 & 0.0002 & 0.0021 \\
\hline$t$-stat & 12.6070 & 3.5199 & 2.6454 & 0.5100 & 5.4200 \\
\hline $\mathrm{CH}-3$ alpha & 0.0063 & 0.0014 & 0.0010 & 0.0002 & 0.0020 \\
\hline$t$-stat & 12.5762 & 3.5225 & 2.6300 & 0.4821 & 5.3693 \\
\hline FF-3 alpha & 0.0063 & 0.0014 & 0.0010 & 0.0002 & 0.0021 \\
\hline$t$-stat & 12.4690 & 3.4930 & 2.5972 & 0.4690 & 5.4331 \\
\hline \multicolumn{6}{|c|}{ Panel C: $F=H=3$ days } \\
\hline ROI & Highest & 2 & 3 & 4 & Lowest \\
\hline 1F alpha & 0.0052 & 0.0015 & 0.0010 & 0.0001 & 0.0016 \\
\hline$t$-stat & 8.9597 & 3.0806 & 2.3848 & 0.1668 & 3.6955 \\
\hline $\mathrm{CH}-3$ alpha & 0.0052 & 0.0015 & 0.0010 & 0.00005 & 0.0016 \\
\hline$t$-stat & 8.9300 & 3.0850 & 2.3652 & 0.1085 & 3.6304 \\
\hline FF-3 alpha & 0.0051 & 0.0015 & 0.0011 & 0.0001 & 0.0016 \\
\hline$t$-stat & 8.8141 & 3.0514 & 2.3829 & 0.1534 & 3.7256 \\
\hline \multicolumn{6}{|c|}{ Panel D: $F=H=30$ days } \\
\hline ROI & Highest & 2 & 3 & 4 & Lowest \\
\hline 1F alpha & -0.0285 & -0.0251 & -0.0236 & -0.0222 & -0.0192 \\
\hline$t$-stat & -19.3416 & -18.0918 & -17.6604 & -16.5880 & -14.1780 \\
\hline $\mathrm{CH}-3$ alpha & -0.0285 & -0.0250 & -0.0236 & -0.0222 & -0.0193 \\
\hline$t$-stat & -19.3661 & -18.0459 & -17.6647 & -16.5807 & -14.2392 \\
\hline FF-3 alpha & -0.0284 & -0.0250 & -0.0235 & -0.0221 & -0.0191 \\
\hline$t$-stat & -19.2355 & -17.9866 & -17.5366 & -16.4639 & -14.0597 \\
\hline \multicolumn{6}{|c|}{ Panel E: $F=H=180$ days } \\
\hline ROI & Highest & 2 & 3 & 4 & Lowest \\
\hline 1F alpha & -0.0523 & -0.0483 & -0.0428 & -0.0392 & -0.0291 \\
\hline$t$-stat & -16.9308 & -16.3887 & -14.3305 & -13.4320 & -10.0824 \\
\hline $\mathrm{CH}-3$ alpha & -0.0524 & -0.0483 & -0.0429 & -0.0394 & -0.0292 \\
\hline$t$-stat & -16.9177 & -16.3102 & -14.3240 & -13.4106 & -10.0567 \\
\hline FF-3 alpha & -0.0517 & -0.0477 & -0.0424 & -0.0388 & -0.0289 \\
\hline$t$-stat & -16.7266 & -16.1821 & -14.2409 & -13.3209 & -9.9843 \\
\hline
\end{tabular}

This table presents the risk-adjusted daily momentum profits (MP) and related $t$-statistics $(t$-stat) for A-share stocks. $F$ and $H$ denote the length of the formation and holding periods, respectively. For each day, we calculate the daily relative order imbalance for every stock and sort the stocks according to the daily relative order imbalance for that day. For each group based on previous sorts, we select winner and loser stocks according to the past price growth rate in the formation period and then calculate winner-minus-loser return spreads in the holding period. We first test the momentum profits in the very short run. The most natural choice is 1 day and we also calculate momentum profits for 2 days and 3 days for robustness. In addition, we further test the momentum profits for 30 days and 180 days to see how they behave in the relatively long run. The sorts based on the daily relative order imbalance (ROI) are categorized into 5 groups. Winner stocks are based on the one-fifth of stocks with the highest price growth rate, while loser stocks are based on the one-fifth of stocks with the lowest price growth rate. The dependent variables are the winner-minus-loser return spreads for different levels of the ROI. $1 \mathrm{~F}$ alpha denotes the regression intercept for the capital asset pricing model, CH-3 alpha is the regression intercept for the Chinese three-factor asset pricing model, and FF-3 alpha is the regression intercept for the Fama-French three-factor asset pricing model. The alphas are the risk-adjusted momentum profits. The $t$-statistics are based on White [68] heteroskedasticity-consistent standard errors according to Liu et al. [38]. The formation and holding periods have the same length according to Verardo [66], Avramov et al. [67], and Hillert et al. [31]. The critical value of 5\% significance of $t$-statistic is 1.96 .

relative order imbalance for extensions. The corresponding momentum profits and $t$-statistics are shown in Figures 5 and 6.

Figure 5 shows the effect of the highest accumulative relative order imbalance for extensions. The results for these extensions are very similar to those in our previous analysis. Overall, the momentum profits change from -0.01 to 0.002 but the major part of momentum profits is smaller than 0 .
The momentum profits are significantly positive in the very short run with the $t$-statistics lying between 2.5 and 10 . When it comes to the long run, the surfaces of the momentum profits and $t$-statistics dramatically move down, implying that the highest accumulative relative order imbalance activates a price reversal. These outcomes suggest that the highest accumulative anxiety (highest accumulative 
TABLE 5: The effect of the accumulative relative order imbalance after risk adjustments of the A-share market.

\begin{tabular}{|c|c|c|c|c|c|}
\hline \multicolumn{6}{|c|}{ Panel A: $F=H=1$ day } \\
\hline ACCI & Highest & 2 & 3 & 4 & Lowest \\
\hline $1 \mathrm{~F}$ alpha & 0.0026 & 0.0028 & 0.0027 & 0.0035 & 0.0064 \\
\hline$t$-stat & 8.9064 & 9.0696 & 8.1529 & 9.9282 & 15.6850 \\
\hline $\mathrm{CH}-3$ alpha & 0.0026 & 0.0029 & 0.0027 & 0.0035 & 0.0064 \\
\hline$t$-stat & 8.8959 & 9.1000 & 8.1425 & 9.8894 & 15.6560 \\
\hline FF-3 alpha & 0.0026 & 0.0029 & 0.0027 & 0.0035 & 0.0064 \\
\hline$t$-stat & 8.8242 & 8.9779 & 8.0365 & 9.8559 & 15.4857 \\
\hline \multicolumn{6}{|c|}{ Panel B: $F=H=2$ days } \\
\hline ACCI & Highest & 2 & 3 & 4 & Lowest \\
\hline $1 \mathrm{~F}$ alpha & 0.0013 & 0.0017 & 0.0010 & 0.0009 & 0.0036 \\
\hline$t$-stat & 3.3869 & 4.3199 & 2.2945 & 2.0152 & 6.9145 \\
\hline $\mathrm{CH}-3$ alpha & 0.0013 & 0.0017 & 0.0010 & 0.0009 & 0.0036 \\
\hline$t$-stat & 3.3529 & 4.2977 & 2.2881 & 1.9869 & 6.8961 \\
\hline FF-3 alpha & 0.0013 & 0.0018 & 0.0009 & 0.0009 & 0.0036 \\
\hline$t$-stat & 3.3662 & 4.2934 & 2.2162 & 1.9870 & 6.8305 \\
\hline \multicolumn{6}{|c|}{ Panel $C: F=H=3$ days } \\
\hline ACCI & Highest & 2 & 3 & 4 & Lowest \\
\hline 1F alpha & 0.0012 & 0.0018 & 0.0013 & 0.0002 & 0.0027 \\
\hline$t$-stat & 2.7346 & 3.9028 & 2.6414 & 0.3550 & 4.5375 \\
\hline CH-3 alpha & 0.0012 & 0.0018 & 0.0013 & 0.0002 & 0.0027 \\
\hline$t$-stat & 2.6988 & 3.8771 & 2.6310 & 0.3066 & 4.5234 \\
\hline FF-3 alpha & 0.0012 & 0.0018 & 0.0013 & 0.0002 & 0.0027 \\
\hline$t$-stat & 2.7237 & 3.8698 & 2.5721 & 0.2961 & 4.4912 \\
\hline \multicolumn{6}{|c|}{ Panel D: $F=H=30$ days } \\
\hline ACCI & Highest & 2 & 3 & 4 & Lowest \\
\hline $1 \mathrm{~F}$ alpha & -0.0117 & -0.0181 & -0.0203 & -0.0263 & -0.0315 \\
\hline$t$-stat & -9.0809 & -12.7652 & -14.8693 & -18.8563 & -20.8082 \\
\hline $\mathrm{CH}-3$ alpha & -0.0117 & -0.0181 & -0.0203 & -0.0263 & -0.0315 \\
\hline$t$-stat & -9.0709 & -12.7911 & -14.9030 & -18.8758 & -20.8273 \\
\hline FF-3 alpha & -0.0116 & -0.0181 & -0.0202 & -0.0262 & -0.0315 \\
\hline$t$-stat & -8.9878 & -12.7257 & -14.7757 & -18.6526 & -20.7468 \\
\hline \multicolumn{6}{|c|}{ Panel E: $F=H=180$ days } \\
\hline ACCI & Highest & 2 & 3 & 4 & Lowest \\
\hline 1F alpha & -0.0199 & -0.0251 & -0.0290 & -0.0471 & -0.0667 \\
\hline$t$-stat & -6.7706 & -7.8772 & -9.9016 & -15.5761 & -19.7604 \\
\hline CH-3 alpha & -0.0201 & -0.0251 & -0.0289 & -0.0470 & -0.0667 \\
\hline$t$-stat & -6.7974 & -7.8374 & -9.8577 & -15.5364 & -19.6877 \\
\hline FF-3 alpha & -0.0193 & -0.0246 & -0.0286 & -0.0464 & -0.0663 \\
\hline$t$-stat & -6.6017 & -7.7689 & -9.7518 & -15.3621 & -19.5937 \\
\hline
\end{tabular}

This table reports the risk-adjusted daily momentum profits (MP) and related $t$-statistics ( $t$-stat) for A-share stocks. $F$ and $H$ represent the length of the formation and holding periods, respectively. On each day, the accumulative relative order imbalance (ACCI = neg $\%$ - pos\%) of every stock is acquired in the formation period and the stocks are initially classified according to the ACCI. Then, for each group based on previous classifications, the stocks are sorted by their past price growth rates in the formation period in order to identify winner and loser stocks. Winner-minus-loser return spreads in the holding periods are then calculated. We first test the momentum profits in the very short run. The most natural choice is 1 day, and we also calculate the momentum profits for 2 days and 3 days for robustness. In addition, we further test the momentum profits for 30 days and 180 days to see how they behave in the relatively long run. The sorts on ACCI are categorized into 5 groups. Winner stocks comprise the one-fifth of stocks with the highest price growth rate, while loser stocks comprise the one-fifth of stocks with the lowest price growth rate. The dependent variables are the winner-minus-loser return spreads under different levels of ACCI. $1 \mathrm{~F}$ alpha denotes the regression intercept of the capital asset pricing model, $\mathrm{CH}-3$ alpha is the regression intercept of the Chinese three-factor asset pricing model, and FF-3 alpha is the regression intercept of the Fama-French three-factor asset pricing model. The alphas are the risk-adjusted momentum profits. The $t$-statistics are based on White [68] heteroskedasticity-consistent standard errors according to Liu et al. [38]. The formation and holding periods have the same length according to Verardo [66], Avramov et al. [67], and Hillert et al. [31]. The critical value of 5\% significance of $t$-statistic is 1.96.

relative order imbalance) leads to price momentum in the short run but becomes restricted in terms of the price reversal in the long run.

We report the effect of the lowest accumulative anxiety (lowest accumulative relative order imbalance) in extensions as shown in Figure 6. Overall, although there are positive momentum profits, most of momentum profits are below 0 . The absolute $t$-statistics in Figure 6 range from 15 to 20, and they are much larger than those in Figure 5 (the maximum absolute $t$-statistic is just 10). In addition, the absolute momentum profits vary from 0.005 to 0.03 in Figure 6, but those in Figure 5 lie only between 0.002 and 0.01 . Regardless of the short run or long run, the absolute momentum profits under the lowest accumulative anxiety are higher than those under the highest accumulative anxiety. Consequently, the influences of the lowest 

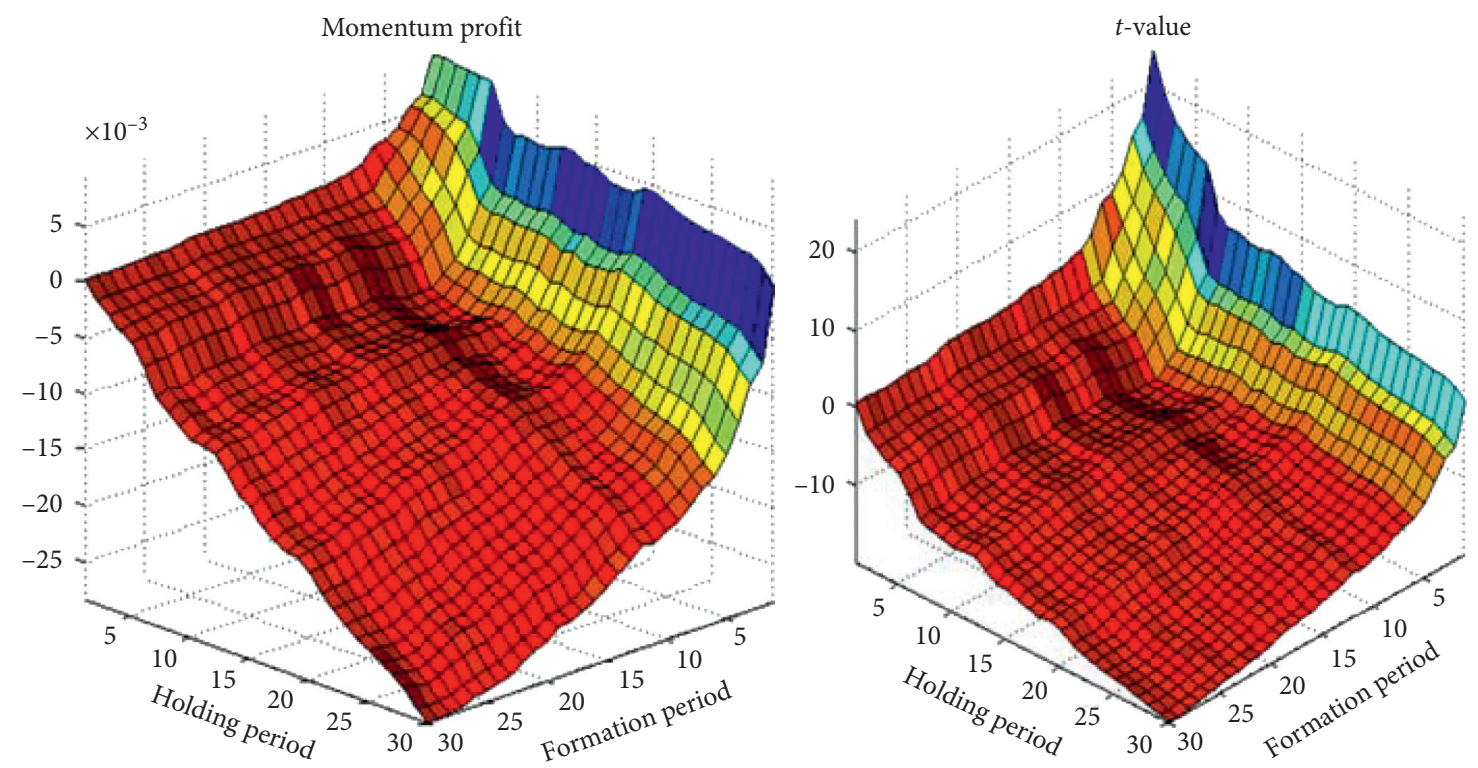

FIgURE 3: Highest daily relative order imbalance in extensions of the A-share market. This figure plots the daily momentum profits and their $t$-statistics under the highest daily relative order imbalance in A-share market. The formation and holding periods, respectively, range from 1 day to 30 days.
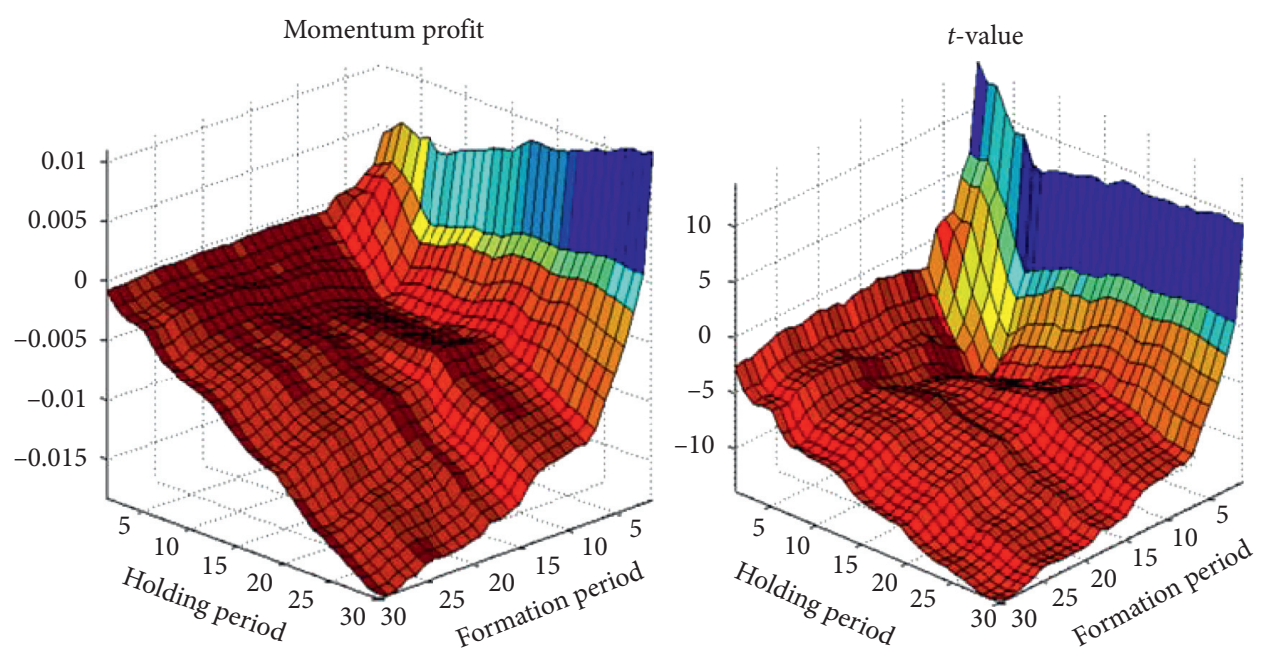

FIGURE 4: Lowest daily relative order imbalance in extensions of the A-share market. This figure plots the daily momentum profits and their $t$-statistics under the lowest daily relative order imbalance in A-share market. The formation and holding periods, respectively, range from 1 day to 30 days.

accumulative anxiety on price momentum or reversal are still stronger than the influences of the highest accumulative anxiety in extended periods.

\section{Empirical Results of the B-Share Market}

This section dedicates to settling the effects of anxiety on momentum profits in the B-share market from the perspectives of instantaneous and accumulative anxiety. We first test the momentum profits in 1 day, 2 days, 3 days, 30 days, and 90 days. In addition, we examine the momentum profits in extended periods. This section aims at comparing whether different investor structures of A-share and B-share markets have influences on the effects of anxiety on momentum profits. According to China Stock Market and Accounting Research, there are just $19.7156 \%$ of A-shares which are held by institutional investors, while there are still $23.3345 \%$ of $\mathrm{B}$-shares belonging to institutional investors. It is obvious that the power of institutional investors in B-share market is stronger than that in A-share market. The detailed data of the proportion of institutional investors are given in Appendix C.

4.1. Momentum Profits of the B-Share Market in Various Periods. We present the momentum profits of the B-share market as a whole in this section. The formation and holding 

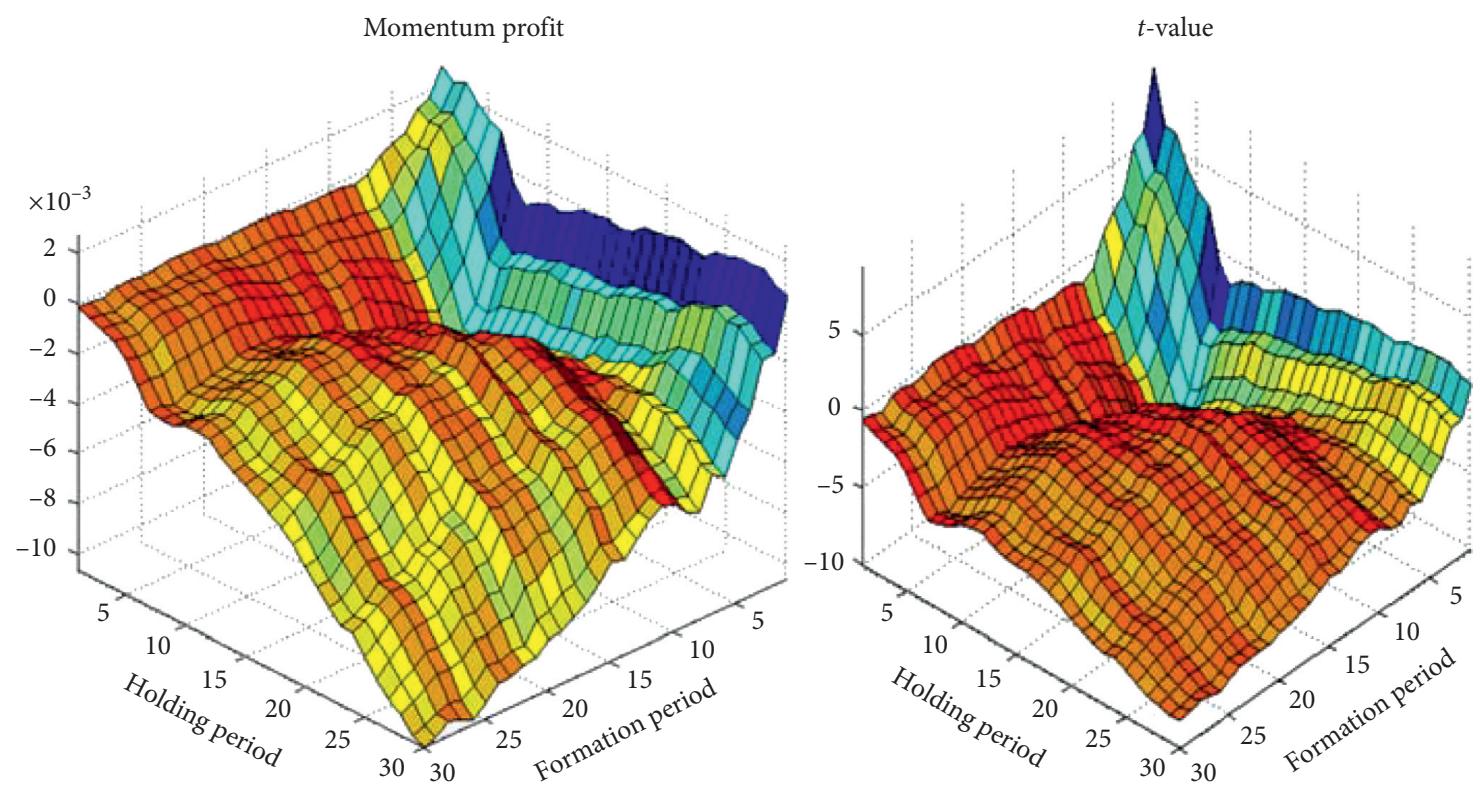

Figure 5: Highest accumulative relative order imbalance in extensions of the A-share market. This figure plots the daily momentum profits and their $t$-statistics under the highest accumulative relative order imbalance in A-share market. The formation and holding periods, respectively, range from 1 day to 30 days.
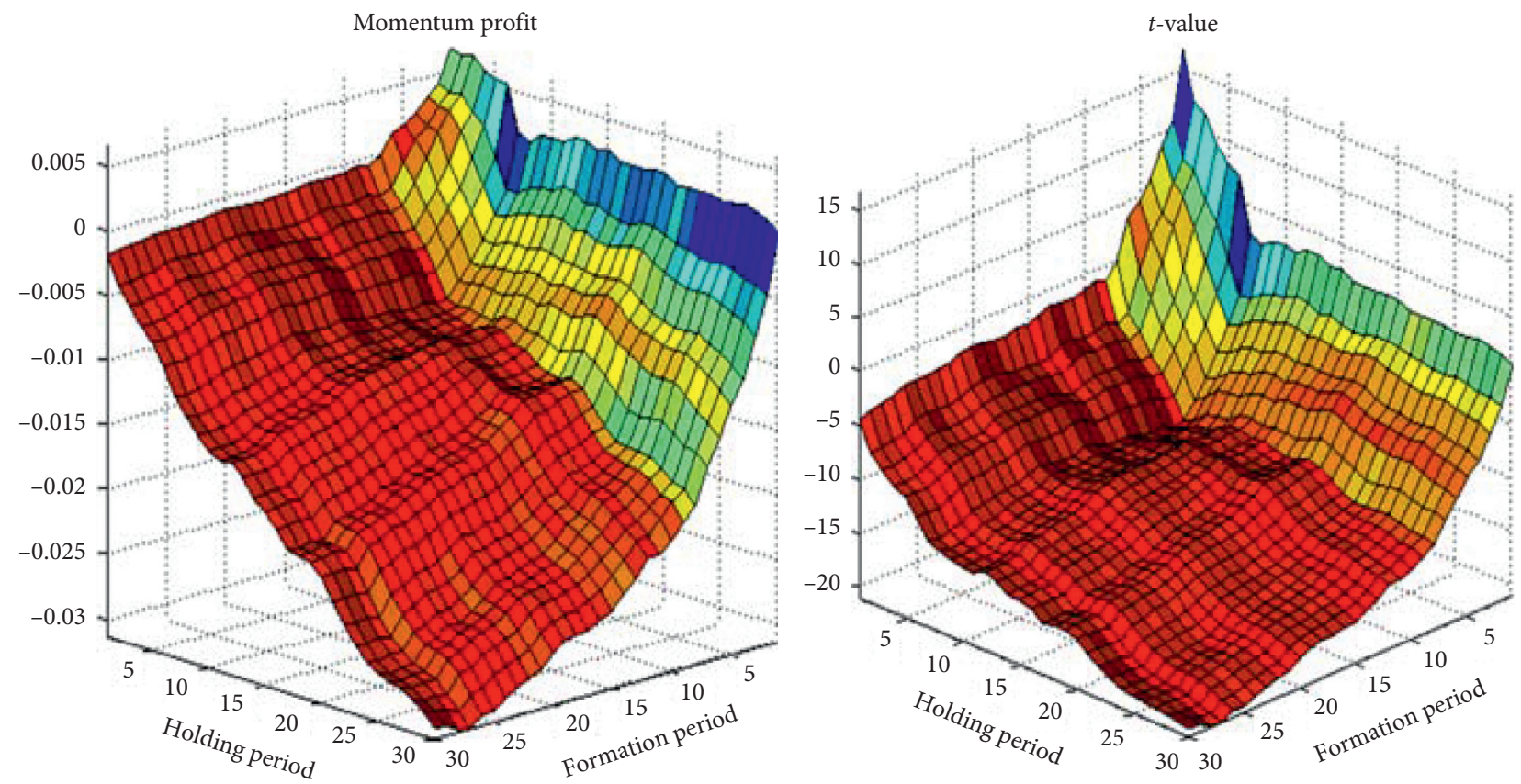

FIGURE 6: Lowest accumulative relative order imbalance in extensions of the A-share market. This figure plots the daily momentum profits and their $t$-statistics under the lowest accumulative relative order imbalance in A-share market. The formation and holding periods, respectively, range from 1 day to 30 days.

periods, respectively, vary from 1 day to 30 days. Figure 7 shows the results.

The momentum profits in Figure 7 show that the B-share market mainly embodies price momentum. Among many momentum profits we show above, they are significantly positive with absolute $t$-statistics higher than 2 . Some of the positive momentum profits even have absolute $t$-statistics over 10 or 12 . There are also significantly negative momentum profits in the figure, but they generally tend to be insignificant as presented in the blue part of the figure.

4.2. Investor Anxiety and Momentum Profits of the B-Share Market. We, respectively, analyze the effects of instantaneous and accumulative anxiety on momentum profits by 


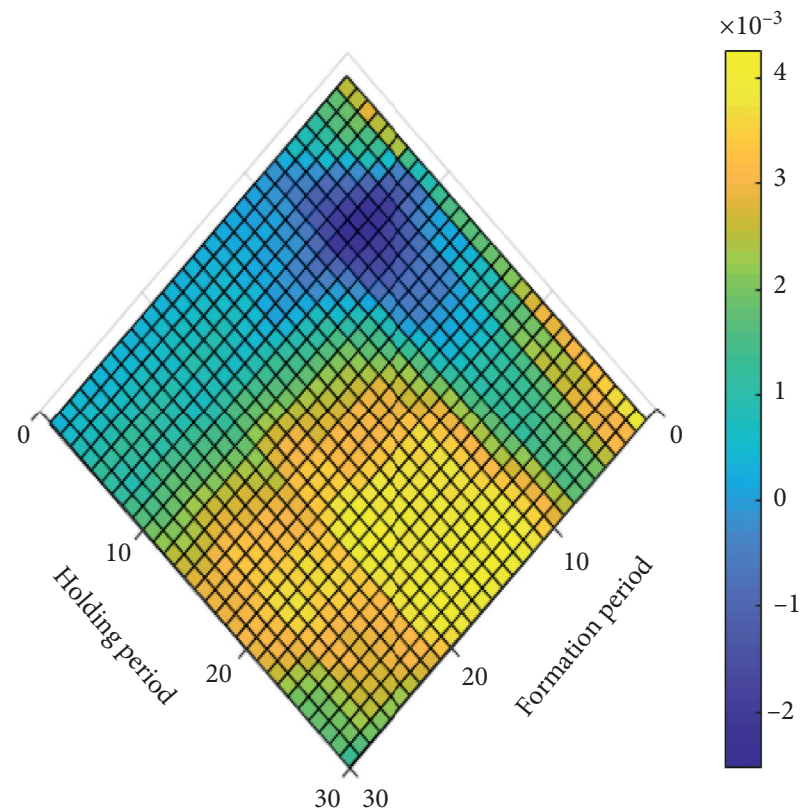

(a)

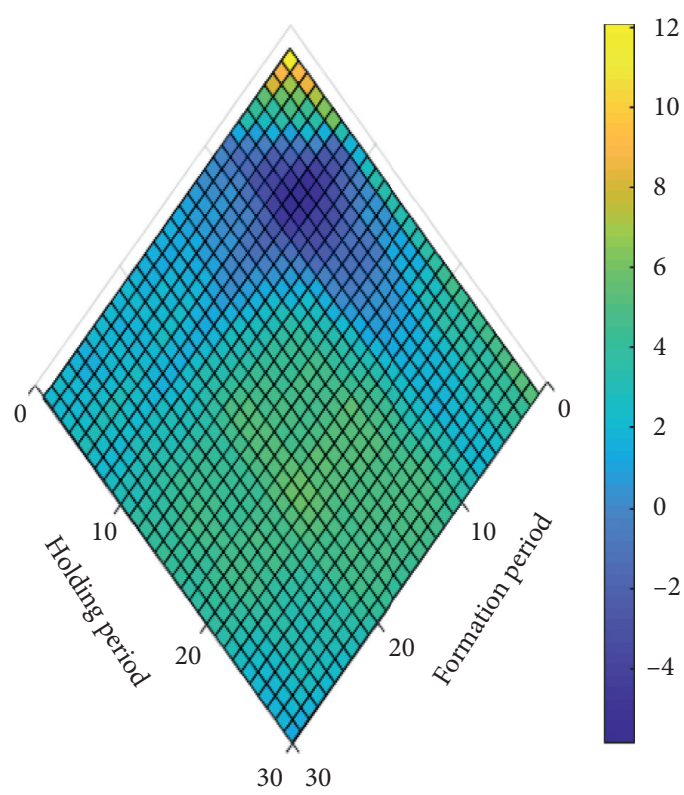

(b)

Figure 7: Momentum profits of the B-share market as a whole. This figure plots the momentum profits and related $t$-statistics of the B-share market as a whole. The formation and holding periods, respectively, range from 1 day to 30 days. (a) Momentum profit and (b) $t$-statistics.

daily relative order imbalance and accumulative relative order imbalance. Table 6 shows the results of daily relative order imbalance, whereas the results of accumulative relative order imbalance are given in Table 7.

As for B-share stocks in Table 6, instantaneous anxiety (daily relative order imbalance) does not appear to have any influence on momentum profits. In the very short run, most of the momentum profits are positive, but they are not very significant as many absolute $t$-statistics are below 1.96. However, when reaching the long run of 30 days and 90 days, the effect of instantaneous anxiety is also unclear and very weak. In 90 days, the momentum profits under the highest and the lowest daily relative order imbalance are all insignificant (absolute $t$-statistics are below 1.96), though those from 30 days are significant due to absolute $t$-statistics being higher than 1.96. Moreover, there is no sufficient evidence supporting that the changes in instantaneous anxiety affect the momentum profits since related $p$ values of $F$-statistics are over 5\%. Hence, based on the findings above, we can imply that instantaneous anxiety only affects the A-share stocks, while no sufficient evidence documents that B-share stocks fall under the shadow of instantaneous anxiety.

Similarly, from the viewpoint of accumulative anxiety (accumulative relative order imbalance), we do not find B-share stocks are influenced by anxiety in Table 7. For 1 day, 2 days, and 3 days, many absolute $t$-statistics are less than 1 regardless of the signs of the momentum profits. In addition, in the long run, many absolute $t$-statistics are still below 1.96. Furthermore, the $p$ values of $F$-statistics are all higher than $5 \%$, so there is no sufficient evidence supporting that the changes in accumulative anxiety affect the momentum profits in the B-share market. Therefore, regardless of the length of testing periods, the influence of accumulative anxiety is relatively strong for A-share stocks, but no strong evidence suggests that B-share stocks fall into the pitfall of the awful impact from anxiety.

4.3. Extended Periods of the B-Share Market. Like the manner of dissecting A-share market, we also investigate the effects of anxiety on momentum profits in B-share market in extended periods. The formation and holding periods of momentum portfolios vary from 1 day to 30 days. Section 4.3.1 shows the results of daily relative order imbalance and those of accumulative relative order imbalance emerge in Section 4.3.2.

4.3.1. Daily Relative Order Imbalance in Extensions of the $B$-Share Market. This section shows the momentum profits under the highest daily relative order imbalance and the lowest daily relative order imbalance in the B-share market. Figures 8 and 9 depict the outcomes.

From Figure 8, we can see that the momentum profits vary from -0.2 to 0.05 under the highest daily relative order imbalance in extensions of the B-share market. The $t$-statistics are between -6 and 1.8 , but some of them are close to 0 . However, most of $t$-statistics under the highest daily relative order imbalance from the A-share market lie between 5 and 20 or between -5 and -20 . There is just very small number of $t$-statistics from the A-share market being close to 0 , suggesting the effect of the highest daily relative order imbalance is stronger in A-share market than in B-share market.

In Figure 9, the momentum profits under the lowest daily relative order imbalance change from -0.15 to 0.05 in 
TABLE 6: The effect of the daily relative order imbalance of the Bshare market.

\begin{tabular}{|c|c|c|c|}
\hline \multicolumn{4}{|c|}{ Panel A: $F=H=1$ Day } \\
\hline ROI & Highest & 2 & Lowest \\
\hline MP & 0.008 & -0.0006 & 0.02 \\
\hline$t$-stat & 0.4765 & -0.0544 & 1.56 \\
\hline \multicolumn{2}{|c|}{$F$-stat $(\mathrm{SFE})$} & \multicolumn{2}{|c|}{0.9990} \\
\hline \multicolumn{2}{|c|}{$p$-value } & \multicolumn{2}{|c|}{0.4057} \\
\hline \multicolumn{4}{|c|}{ Panel B: $F=H=2$ days } \\
\hline ROI & Highest & 2 & Lowest \\
\hline MP & 0.0057 & 0.0011 & 0.0164 \\
\hline$t$-stat & 0.2126 & 0.0761 & 1.7463 \\
\hline \multicolumn{2}{|c|}{$F$-stat $(\mathrm{SFE})$} & \multicolumn{2}{|c|}{0.3047} \\
\hline \multicolumn{2}{|c|}{$p$ value } & \multicolumn{2}{|c|}{0.7446} \\
\hline \multicolumn{4}{|c|}{ Panel C: $F=H=3$ days } \\
\hline ROI & Highest & 2 & Lowest \\
\hline MP & -0.0145 & -0.0244 & 0.0517 \\
\hline$t$-stat & -0.586 & -1.0882 & 2.6181 \\
\hline \multicolumn{2}{|c|}{$F$-stat $(\mathrm{SFE})$} & \multicolumn{2}{|c|}{1.7797} \\
\hline \multicolumn{2}{|c|}{$p$ value } & \multicolumn{2}{|c|}{0.2232} \\
\hline \multicolumn{4}{|c|}{ Panel D: $F=H=30$ days } \\
\hline ROI & Highest & 2 & Lowest \\
\hline MP & -0.1396 & -0.0481 & -0.108 \\
\hline$t$-stat & -3.8853 & -1.4117 & -2.3744 \\
\hline \multicolumn{2}{|c|}{$F$-stat $(\mathrm{SFE})$} & \multicolumn{2}{|c|}{0.4224} \\
\hline \multicolumn{2}{|c|}{$p$ value } & \multicolumn{2}{|c|}{0.6649} \\
\hline \multicolumn{4}{|c|}{ Panel E: $F=H=90$ days } \\
\hline ROI & Highest & 2 & Lowest \\
\hline $\mathrm{MP}$ & -0.1405 & -0.0965 & 0.0343 \\
\hline$t$-stat & -1.7508 & -3.7581 & 1.0548 \\
\hline \multicolumn{2}{|c|}{$F$-stat $(\mathrm{SFE})$} & \multicolumn{2}{|c|}{2.2867} \\
\hline \multicolumn{2}{|c|}{$p$ value } & \multicolumn{2}{|c|}{0.1827} \\
\hline
\end{tabular}

This table presents the daily momentum profits (MP) and related $t$-statistics $(t-$ stat) of B-share stocks. $F$ and $H$ represent the length of the formation and holding periods, respectively. For each day, we calculate the daily relative order imbalance for every stock and sort the stocks according to the daily relative order imbalance for that day. Within each group based on previous sorts, we select the winner and loser stocks according to the past price growth rate in the formation period and then calculate the momentum profit (average winner-minus-loser return spread) in the holding period. According to [65], our analyses for the effects of ROI on momentum profits are single-factor experiments (SFE), so we calculate F-statistics to test if the winner-minus-loser return spreads from different groups have the same average values. We first test the momentum profits in the very short run. The most natural choice is 1 day, and we also calculate the momentum profits for 2 days and 3 days for robustness. In addition, we further test the momentum profits for 30 days and 90 days to see how they behave in the relatively long run. The sorts based on the daily relative order imbalance (ROI) are classified into 3 groups. Winner stocks are the one-third of stocks with the highest price growth rate, while loser stocks are the one-third of stocks with the lowest price growth rate. The choices involving 90 days and one-third of the classifications are due to the small sample of B-share stocks (approximately 100 stocks). The formation and holding periods have the same length according to Verardo [66], Avramov et al. [67], and Hillert et al. [31]. The critical value of 5\% significance of $t$-statistic is 1.96 .

the B-share market, which is similar to those from the highest daily relative order imbalance. In addition, the $t$ statistics are between -5 and 4 , but many of them are close to 0 . The momentum profits and $t$-statistics under the lowest daily relative order imbalance do not vary a lot from those under the highest daily relative order imbalance. Hence, no strong evidence shows the daily relative order imbalance
TABLE 7: The effect of the accumulative relative order imbalance of the B-share market.

\begin{tabular}{|c|c|c|c|}
\hline \multicolumn{4}{|c|}{ Panel A: $F=H=1$ day } \\
\hline ACCI & Highest & 2 & Lowest \\
\hline MP & 0.0132 & 0.0124 & 0.0187 \\
\hline$t$-stat & 0.9139 & 0.6781 & 0.9135 \\
\hline \multicolumn{2}{|c|}{ F-stat (SFE) } & \multicolumn{2}{|c|}{3.8613} \\
\hline \multicolumn{2}{|c|}{$p$ value } & \multicolumn{2}{|c|}{0.0836} \\
\hline \multicolumn{4}{|c|}{ Panel B: $F=H=2$ days } \\
\hline ACCI & Highest & 2 & Lowest \\
\hline MP & 0.0509 & -0.0081 & 0.035 \\
\hline$t$-stat & 2.0079 & -0.2416 & 0.9545 \\
\hline \multicolumn{2}{|c|}{$F$-stat (SFE) } & \multicolumn{2}{|c|}{2.8923} \\
\hline \multicolumn{2}{|c|}{$p$ value } & \multicolumn{2}{|c|}{0.1320} \\
\hline \multicolumn{4}{|c|}{ Panel C: $F=H=3$ days } \\
\hline ACCI & Highest & 2 & Lowest \\
\hline MP & 0.0592 & -0.0237 & 0.0212 \\
\hline$t$-stat & 8.627 & -0.5423 & 0.5729 \\
\hline \multirow{2}{*}{\multicolumn{2}{|c|}{ F-stat (SFE) }} & \multicolumn{2}{|c|}{3.1636} \\
\hline & & \multicolumn{2}{|c|}{0.1153} \\
\hline \multicolumn{4}{|c|}{ Panel D: $F=H=30$ days } \\
\hline ACCI & Highest & 2 & Lowest \\
\hline MP & -0.1317 & -0.0748 & -0.0787 \\
\hline$t$-stat & -2.3276 & -1.4707 & -1.8586 \\
\hline \multirow{2}{*}{\multicolumn{2}{|c|}{$\begin{array}{c}F \text {-stat }(\mathrm{SFE}) \\
p \text { value }\end{array}$}} & \multicolumn{2}{|c|}{0.0976} \\
\hline & & \multicolumn{2}{|c|}{0.9078} \\
\hline \multicolumn{4}{|c|}{ Panel E: $F=H=90$ days } \\
\hline $\mathrm{ACCI}$ & Highest & 2 & Lowest \\
\hline MP & -0.0757 & 0.0232 & -0.1043 \\
\hline$t$-stat & -1.5088 & 0.7588 & -2.1721 \\
\hline \multicolumn{2}{|c|}{$F$-stat (SFE) } & \multicolumn{2}{|c|}{1.5604} \\
\hline \multicolumn{2}{|c|}{$p$ value } & \multicolumn{2}{|c|}{0.2847} \\
\hline
\end{tabular}

This table presents the daily momentum profits (MP) and related $t$-statistics ( $t$-stat) of B-share stocks. $F$ and $H$ represent the length of the formation and holding periods, respectively. On each day, the accumulative relative order imbalance (ACCI $=$ neg $\%$ - pos\%) for each stock is obtained in the formation period, and we initially classify the stocks based on ACCI. Then, in each group from the previous classifications, the stocks are sorted based on the past price growth rate in the formation period in order to identify winner and loser stocks. The momentum profits (average winner-minusloser return spread) are thus calculated in the holding period. According to [65], our analyses for the effects of ACCI on momentum profits are singlefactor experiments (SFE), so we calculate $F$-statistics to test if the winnerminus-loser return spreads from different groups have the same average values. We first test the momentum profits in the very short run. The most natural choice is 1 day, and we also calculate the momentum profits for 2 days and 3 days for robustness. In addition, we further test the momentum profits for 30 days and 90 days to see how they behave in the relatively long run. The sorts based on ACCI are categorized into 3 groups. Winner stocks consist of the one-third of stocks with the highest price growth rate, while loser stocks are made up of the one-third of stocks with the lowest price growth rate. The choices of 90 days and three group classifications arise due to the small sample of B-share stocks (approximately 100 stocks). The formation and holding periods have the same length according to Verardo [66], Avramov et al. [67], and Hillert et al. [31]. The critical value of 5\% significance of $t$-statistic is 1.96 .

affects the momentum profits in extensions of the B-share market. Moreover, there are just small number of $t$-statistics under the lowest daily relative order imbalance from A-share market being close to 0 , so the effect of the lowest daily relative order imbalance is stronger in A-share market. 

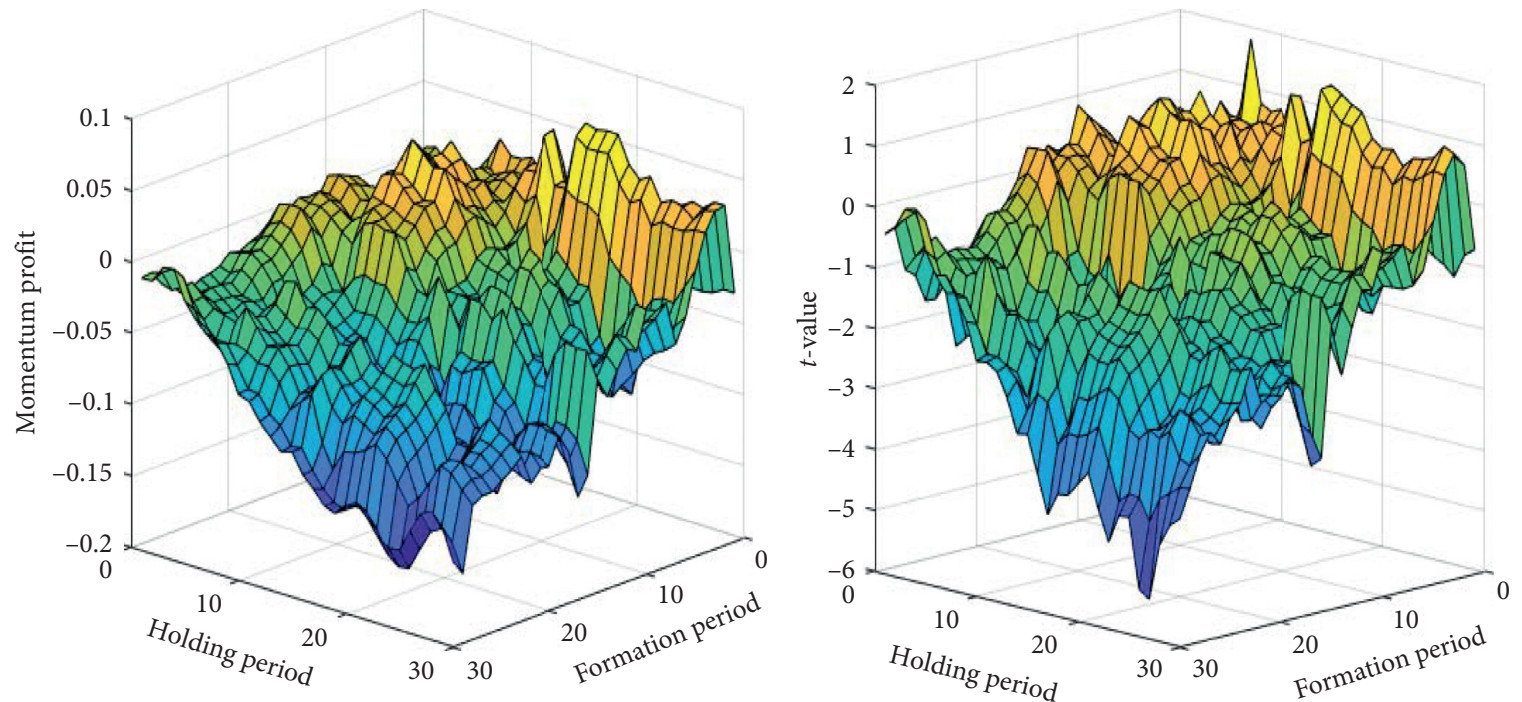

FIgURE 8: Highest daily relative order imbalance in extensions of the B-share market. This figure shows the momentum profits and $t$ statistics under the highest daily relative order imbalance in extensions of the B-share market. The formation and holding periods, respectively, range from 1 day to 30 days.
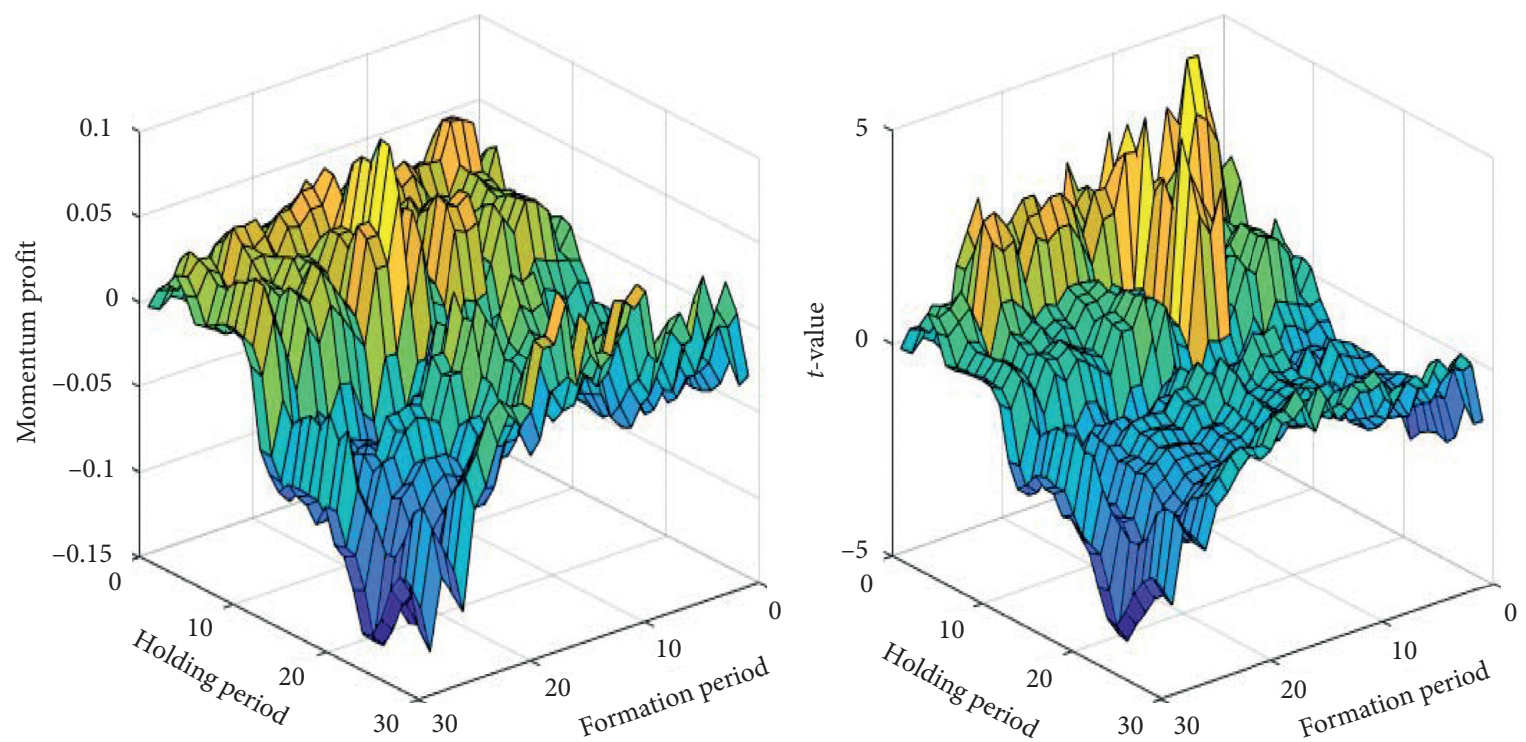

FiguRE 9: Lowest daily relative order imbalance in extensions of the B-share market. This figure shows the momentum profits and $t$-statistics under the lowest daily relative order imbalance in extensions of the B-share market. The formation and holding periods, respectively, range from 1 day to 30 days.

\subsubsection{Accumulative Relative Order Imbalance in Extensions} of the B-Share Market. In this section, we show the momentum profits and $t$-statistics under the highest accumulative relative order imbalance and the lowest accumulative relative order imbalance in extensions of the B-share market. Figures 10 and 11 contain the outcomes.

We can see that the momentum profits vary from -0.15 to 0.05 under the highest accumulative relative order imbalance from Figure 10 . In addition, the $t$-statistics lie between -4 and 8 . The majority of absolute $t$-statistics changes around 2, but some of them are close to 0 . However, the counterpart of $t$-statistics from A-share market varies from
-10 to 10 , which is much higher than the B-share market. In addition, just a small number of $t$-statistics in A-share market approaches 0 . Overall, the effect of the highest accumulative relative order imbalance is stronger in A-share market than in B-share market.

From Figure 11, we know that the momentum profits are between -0.2 and 0.06 under the lowest accumulative relative order imbalance, which is similar to those from the highest accumulative relative order imbalance. Moreover, most of absolute $t$-statistics under the lowest accumulative relative order imbalance are over 2 and some of them are close to 0 , which is also similar to those under the highest 

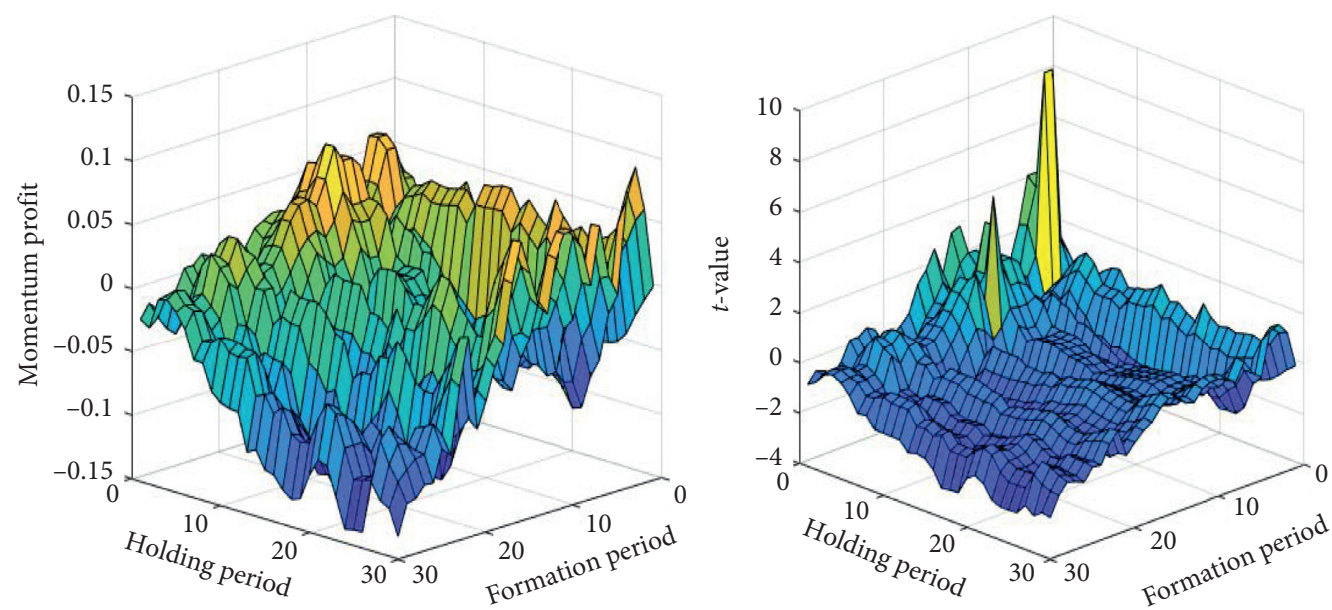

Figure 10: Highest accumulative relative order imbalance in extensions of the B-share market. This figure shows the momentum profits and $t$-statistics under the highest accumulative relative order imbalance in extensions of the B-share market. The formation and holding periods, respectively, range from 1 day to 30 days.
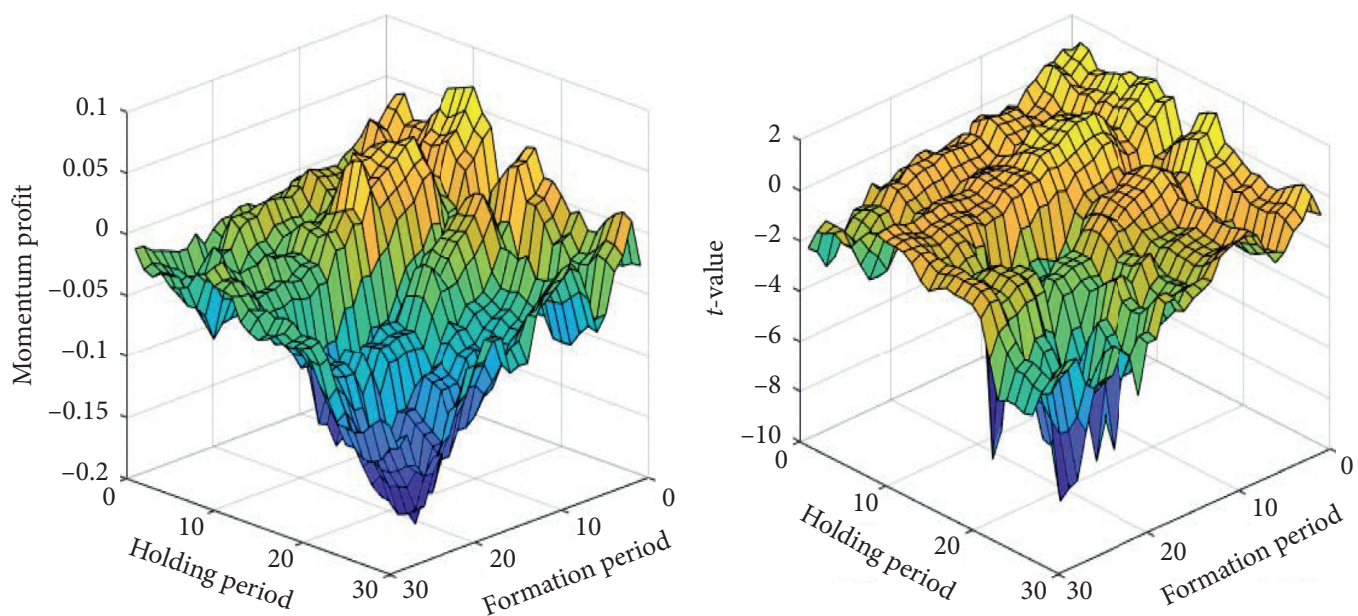

FIgURE 11: Lowest accumulative relative order imbalance in extensions of the B-share market. This figure shows the momentum profits and $t$-statistics under the lowest accumulative relative order imbalance in extensions of the B-share market. The formation and holding periods, respectively, range from 1 day to 30 days.

accumulative relative order imbalance. These outcomes suggest that no evidence proves accumulative relative order imbalance affects momentum profits in the B-share market. Furthermore, the counterpart of absolute $t$-statistics from A-share market is mainly over 5 and there is just very small number of them reaching 0 , implying that the effect of the lowest accumulative relative order imbalance is also stronger in A-share market than in B-share market.

\section{Robustness Checks}

In Section 3, our analyses for the effects of anxiety on momentum profits in the A-share market are based on a 5group basis, so we retest the effects of anxiety on momentum profits by 3 -group analyses. Because no effect of anxiety on momentum profits is observed in all testing periods by 3 group analyses in the B-share market, we do not check the results here. Table 8 detects instantaneous anxiety (the daily relative order imbalance), and Table 9 investigates accumulative anxiety (the accumulative relative order imbalance).

From Table 8, it can be seen that the results for the Chinese A-share stocks are totally consistent with prior findings. The lowest instantaneous anxiety (highest daily relative order imbalance) generates the most significantly positive momentum profits in the very short run (the $t$ statistics are $18.116,8.7766$, and 5.0269, respectively, for the 1-day, 2-day, and 3-day periods). In the relatively long run comprising 30 days and 90 days, the lowest instantaneous anxiety turns to generate the most significantly negative momentum profits (the absolute $t$-statistics are 23.6567 and 28.479 , respectively). The highest instantaneous anxiety (lowest daily relative order imbalance) stocks have the least significantly negative momentum profits with absolute $t$ statistics no higher than 22 . These outcomes again prove that the lowest instantaneous anxiety most violently 
TABLE 8: The effect of the daily relative order imbalance: three groups.

\begin{tabular}{|c|c|c|c|}
\hline \multicolumn{4}{|c|}{ Panel A: $F=H=1$ day } \\
\hline ROI & Highest & 2 & Lowest \\
\hline MP & 0.0043 & 0.0010 & 0.0025 \\
\hline$t$-stat & 18.1160 & 5.1436 & 12.0772 \\
\hline \multicolumn{4}{|c|}{ Panel B: $F=H=2$ days } \\
\hline ROI & Highest & 2 & Lowest \\
\hline MP & 0.0027 & 0.0001 & 0.0009 \\
\hline$t$-stat & 8.7766 & 0.4354 & 3.3701 \\
\hline \multicolumn{4}{|c|}{ Panel C: $F=H=3$ days } \\
\hline ROI & Highest & 2 & Lowest \\
\hline MP & 0.0018 & 0.0000 & 0.0006 \\
\hline$t$-stat & 5.0259 & 0.0732 & 2.0503 \\
\hline \multicolumn{4}{|c|}{ Panel D: $F=H=30$ days } \\
\hline ROI & Highest & 2 & Lowest \\
\hline MP & -0.0218 & -0.0177 & -0.0153 \\
\hline$t$-stat & -23.6567 & -19.6732 & -16.5390 \\
\hline \multicolumn{4}{|c|}{ Panel E: $F=H=90$ days } \\
\hline ROI & Highest & 2 & Lowest \\
\hline MP & -0.0422 & -0.0353 & -0.0306 \\
\hline$t$-stat & -28.4790 & -24.1903 & -21.3626 \\
\hline
\end{tabular}

This table presents the daily momentum profits (MP) and related $t$-statistics ( $t$-stat) of the A-share stocks. $F$ and $H$ represent the length of the formation and holding periods, respectively. For each day, we calculate the daily relative order imbalance for every stock and sort the stocks according to the daily relative order imbalance for that day. Within each group based on previous sorts, we select the winner and loser stocks according to the past price growth rate in the formation period and then calculate the momentum profit (average winner-minus-loser return spread) in the holding period. We first test the momentum profits in the very short run. The most natural choice is 1 day, and we also calculate the momentum profits for 2 days and 3 days for robustness. In addition, we further test the momentum profits for 30 days and 90 days to see how they behave in the relatively long run. The sorts based on the daily relative order imbalance (ROI) are classified into 3 groups. Winner stocks are the one-third of stocks with the highest price growth rate, while loser stocks are the one-third of stocks with the lowest price growth rate. The formation and holding periods have the same length according to Verardo [66], Avramov et al. [67], and Hillert et al. [31]. The critical value of $5 \%$ significance of $t$-statistic is 1.96 .

induces price momentum in the very short run but results in price reversals in the long run (we also run the linear regressions by regressing the momentum profit of the market as a whole on daily relative order imbalance of the market as a whole; we find that most of the absolute $t$ statistics of slopes from ROI are higher than 2 or even higher than 6).

In Table 9 on accumulative anxiety, the results remain basically same as what we discovered in Section 3. From the 1-day period in Panel A, for the lowest accumulative anxiety (lowest ACCI), the positive momentum profit obtains the highest value with a $t$-statistic of 11.9803 . In the long run covering 30 days and 90 days, the lowest accumulative anxiety generates the most significantly negative momentum profits with absolute $t$-statistics of 25.327 and 29.6983, respectively. Although for the 2-day and 3-day periods, the lowest accumulative anxiety does not give rise to the most significantly positive momentum profits (the $t$-statistics are 3.4861 and 0.8205 , respectively), the results for the 1 -day, 30 day, and 90-day periods still support what we find in Section
TABLE 9: The effect of the accumulative relative order imbalance: three groups.

\begin{tabular}{lccc}
\hline \multicolumn{4}{c}{ Panel A: $F=H=1$ day } \\
ACCI & Highest & 2 & Lowest \\
\hline MP & 0.0021 & 0.0019 & 0.0029 \\
$t$-stat & 10.2420 & 8.4455 & 11.9803 \\
\hline & Panel B: $F=H=2$ days \\
ACCI & Highest & 2 & Lowest \\
\hline MP & 0.0011 & 0.0006 & 0.0011 \\
$t$-stat & 4.3076 & 2.1889 & 3.4861 \\
\hline \multicolumn{4}{c}{ Panel C: $F=H=3$ days } \\
ACCI & Highest & 2 & \\
\hline MP & 0.0012 & 0.0004 \\
$t$-stat & 3.8767 & 1.3551 & Lowest \\
\hline & Panel D: $F=H=30$ days & 0.0003 \\
ACCI & Highest & 2 & Lowest \\
\hline MP & -0.0110 & -0.0152 \\
$t$-stat & -12.2302 & -17.1343 & -0.0237 \\
\hline & Panel E: $F=H=90$ days \\
ACCI & Highest & 2 & -25.3270 \\
\hline MP & -0.0255 & -0.0338 \\
$t$-stat & -17.8584 & -23.1833 & Lowest \\
\hline
\end{tabular}

This table presents the daily momentum profits (MP) and related $t$-statistics ( $t$-stat) of the A-share stocks. $F$ and $H$ represent the length of the formation and holding periods, respectively. On each day, the accumulative relative order imbalance $(\mathrm{ACCI}=\mathrm{neg} \%$ - pos $\%)$ for each stock is obtained in the formation period and we initially classify the stocks based on ACCI. Then, in each group from the previous classifications, the stocks are sorted based on the past price growth rate in the formation period in order to identify winner and loser stocks. The momentum profits (average winner-minusloser return spread) are thus calculated in the holding period. We first test the momentum profits in the very short run. The most natural choice is 1 day, and we also calculate the momentum profits for 2 days and 3 days for robustness. In addition, we further test the momentum profits for 30 days and 90 days to see how they behave in the relatively long run. The sorts based on ACCI are categorized into 3 groups. Winner stocks consist of the one-third of stocks with the highest price growth rate, while loser stocks are made up of the one-third of stocks with the lowest price growth rate. The formation and holding periods have the same length according to Verardo [66], Avramov et al. [67], and Hillert et al. [31]. The critical value of 5\% significance of $t$-statistic is 1.96 .

3 (we also run the linear regressions by regressing the momentum profit of the market as a whole on the accumulative relative order imbalance of the market as a whole; we find that most of the absolute $t$-statistics of slopes from ACCI range from 4 to 9 ).

\section{Conclusions}

In this paper, we address the effects of investor anxiety on momentum in the Shanghai and Shenzhen stock exchanges from the perspectives of instantaneous anxiety and accumulative anxiety. The stocks held by the least anxious investors generate the strongest price momentum, while the stocks held by the most anxious investors stimulate much weaker momentum. However, when extending the examination periods, we perceive that price reversals prevail across various degrees of anxiety. Moreover, the risk adjustments by asset pricing models document the results are very stable. We infer that the impact of anxiety stems 
TABle 10: Institutional investors in the A-share and B-share markets.

\begin{tabular}{lcc}
\hline Total Average & A-share market & B-share market \\
\hline Investment fund & 4.5718 & 0 \\
Overseas investors & 1.9041 & 2.8366 \\
Brokers & 1.8350 & 2.2429 \\
Insurance corporations & 2.2585 & 0 \\
Security fund & 1.6483 & 0 \\
Entrust fund & 2.6657 & 14.1800 \\
Finance corporations & 1.3673 & 0 \\
Banks & 3.4651 & 4.0750 \\
Total proportion & 19.7156 & 23.3345 \\
\hline
\end{tabular}

This table presents the proportion (percentage) of shares held by institutional investors in the A-share and B-share markets from the year 2007 to the year 2018. The type of institutional investors includes investment fund, overseas investors, brokers, insurance corporations, security fund, entrust fund, finance corporations, and banks.

from the dominant role played by retail investors in the Chinese stock market.

The retail investors lack sufficient professional knowledge and good information sources compared to the institutional investors, so they always confront difficulties in decision making and anxiety behaves as one of their intrinsic characteristics. The lowest degree of anxiety denotes extreme optimism, with the result that the retail investors will not update their information in time in the short run, thereby initially letting mispricing come into being. This tendency implies an underreaction to information, forcing the stock prices to deviate from their fundamentals in the short run and thus price momentum turns to be evident. As time goes by, once the retail investors perceive the upcoming information is beyond expectations, they are possible to overreact to information and adjust past decisions. The initial mispricing will be corrected toward fundamentals and price reversals thus occur.

To the best of our knowledge, past studies detect disposable panic, but they do not devote to the discussions on the intrinsic anxiety from retail investors (e.g., [69-71]). Our experiments based on daily data exactly reflect the day-to-day anxiety from retail investors. Since the Chinese A-share market is tightly dominated by retail investors, the A-share market is very prone to the disturbance from anxiety, so we have no reason to neglect the role of anxiety. One of our notable contributions in this paper is that we discover price reversals of A-share market are derived from the overreactions induced by anxiety, enriching the perceptions on investor behaviors with respect to the effects of intrinsic anxiety from retail investors on momentum and reversal. Overall, we find that the A-share market is more likely to exhibit subtle momentum with higher anxiety, but the B-share market is easier to encounter considerable momentum with lower anxiety.

This research further reveals the behaviors of retail investors in the Chinese stock market. We have discussed instantaneous anxiety and accumulative anxiety in this paper, but an important issue is that how such anxiety transfers among investors. In addition, whether the resulting transfer releases an influence on the stock market should prove to be fruitful in future research.

\section{Appendix}

\section{A. Details of the Conditional Momentum Portfolio}

In the conditional momentum portfolio, the stocks are classified sequentially. Let $\psi$ denote the investor anxiety of every stock in the formation period. First, all stocks are divided into $Q$ groups via $\psi$. Second, in each group stemming from $\psi$, the stocks are further sorted into $Q$ groups according to the formation price growth rate, $P_{G}$. The subscript $Q$ denotes the highest level of the price growth rate or investor anxiety. These two classifications trigger $Q^{2}$ portfolios. The studies of Chang et al. [72], Kim and Suh [59], and Celiker et al. [62] implement the same portfolio.

$$
\operatorname{Con}\left(\psi, P_{G}\right)=\left[\begin{array}{cccc}
\Omega_{t}\left(P_{G, 1} \mid \psi_{1}\right) & \Omega_{t}\left(P_{G, 2} \mid \psi_{1}\right) & \cdots & \Omega_{t}\left(P_{G, Q} \mid \psi_{1}\right) \\
\Omega_{t}\left(P_{G, 1} \mid \psi_{2}\right) & \Omega_{t}\left(P_{G, 2} \mid \psi_{2}\right) & \cdots & \Omega_{t}\left(P_{G, Q} \mid \psi_{2}\right) \\
\vdots & \vdots & \vdots & \vdots \\
\Omega_{t}\left(P_{G, 1} \mid \psi_{Q}\right) & \Omega_{t}\left(P_{G, 2} \mid \psi_{Q}\right) & \cdots & \Omega_{t}\left(P_{G, Q} \mid \psi_{Q}\right)
\end{array}\right] .
$$

From the matrix above, $Q$ momentum profits are obtained as

$$
\begin{aligned}
& \mathrm{MP}_{\psi_{1}}^{\mathrm{Con}}=\frac{1}{n} \sum_{q=1}^{n}\left[\overline{R_{H_{q}}^{\Omega_{t}\left(P_{G, Q} \mid \psi_{1}\right)}}-\overline{R_{H_{q}}^{\Omega_{t}\left(P_{G, 1} \mid \psi_{1}\right)}}\right], \\
& \mathrm{MP}_{\psi_{2}}^{\mathrm{Con}}=\frac{1}{n} \sum_{q=1}^{n}\left[\overline{R_{H_{q}}^{\Omega_{t}\left(P_{G, Q} \mid \psi_{2}\right)}}-\overline{R_{H_{q}}^{\Omega_{t}\left(P_{G, 1} \mid \psi_{2}\right)}}\right] \text {, } \\
& \vdots \\
& \mathrm{MP}_{\psi_{Q}}^{\mathrm{Con}}=\frac{1}{n} \sum_{q=1}^{n}\left[\overline{R_{H_{q}}^{\Omega_{t}\left(P_{G, Q} \mid \psi_{Q}\right)}}-\overline{R_{H_{q}}^{\Omega_{t}\left(P_{G, 1} \mid \psi_{Q}\right)}}\right] .
\end{aligned}
$$

\section{B. Constructions of the Pricing Factors}

The capital asset pricing model, Chinese three-factor asset pricing model [38], and Fama-French three-factor asset pricing model [37] are used in this paper to adjust risks. We describe the construction procedures of these factors in this appendix.

$\mathrm{MKT}_{t}$ : the market risk factor of the capital asset pricing model is calculated as the daily value-weighted market return in excess of the daily risk-free rate.

$\mathrm{SMB}_{t}^{\mathrm{CH}}$ and $\mathrm{VMG}_{t}^{\mathrm{CH}}$ : the Chinese size $\left(\mathrm{SMB}_{t}^{\mathrm{CH}}\right)$ and value $\left(\mathrm{VMG}_{t}^{\mathrm{CH}}\right)$ factors of Liu et al. [38] are calculated as follows. Following Liu et al. [38], in each month $t-1$, we delete the smallest $30 \%$ of stocks in the market based on market capitalization. The remaining $70 \%$ of stocks make up the sample for factor constructions. We sort the stocks into 2 
groups denoted as the big and small groups based on market capitalization in month $t-1$. Independently, the stocks are sorted based on the most recent earnings-to-price ratios into 3 groups constituting the high, medium, and low groups. Besides, the intersections of these sorts give rise to 6 groups and we compute the daily returns of these groups in month $t$. The Chinese size factor is calculated by the simple average of the return spreads between the 3 small groups and 3 big groups (small minus big). The Chinese value factor is the simple average of the return spreads between 2 high groups and 2 low groups (high minus low). The earnings calculation follows the definition in Section 2.5, and so the earnings-toprice ratio is the ratio of earnings to market capitalization. Market capitalization is the product of the stock price and the number of shares.

$\mathrm{SMB}_{t}^{\mathrm{FF}}$ and $\mathrm{HML}_{t}^{\mathrm{FF}}$ : the size $\left(\mathrm{SMB}_{t}^{\mathrm{FF}}\right)$ and value $\left(\mathrm{HML}_{t}^{\mathrm{FF}}\right)$ factors of Fama and French [37] are obtained as follows. According to Fama and French [37], in June of each year $t$, we classify all stocks into 2 groups based on the market capitalization of that month. Independently, all stocks are classified into 3 groups by the book-to-market ratio in December of each year $t-1$. From July of year $t$ to June of year $t+1$, the daily returns of these 6 groups are generated. The Fama-French size factor is the simple average of the return spreads between the 3 small groups and 3 big groups (small minus big), while the corresponding value factor is the simple average of the return spreads between the 2 high groups and 2 low groups (high minus low). The bookto-market ratio is the ratio of book equity to market capitalization.

\section{Proportion of Shares Held by Institutional Investors in the A-Share and B-Share Markets}

This appendix shows the proportion of shares held by institutional investors in the A-share and B-share markets. The type of institutional investors includes investment fund, overseas investors, brokers, insurance corporations, security fund, entrust fund, finance corporations, and banks. The data are collected from China Stock Market and Accounting Research (CSMAR) database.

From Table 10, we can see the proportion of shares held by different types of institutional investors. Although all types of institutional investors hold the A-share stocks, the total proportion is $19.7156 \%$. On the contrary, the total proportion of B-share market is $23.3345 \%$, which is $3.6189 \%$ higher than the A-share market.

\section{Data Availability}

All data used to support the findings of this study were supplied by China Stock Market and Accounting Research (CSMAR) database under license and so cannot be made freely available. Requests for access to these data should be made to GTA corporation (e-mail: market@gtafe.com).

\section{Conflicts of Interest}

The authors declare that they have no conflicts of interest.

\section{References}

[1] C.-M. Cheng, A. YiHou Huang, and M.-C. Hu, "Investor attention and stock price movement," Journal of Behavioral Finance, vol. 20, no. 3, pp. 294-303, 2019.

[2] M. W. Uhl, "Reuters sentiment and stock returns," Journal of Behavioral Finance, vol. 15, no. 4, pp. 287-298, 2014.

[3] C. Antoniou, J. A. Doukas, and A. Subrahmanyam, "Cognitive dissonance, sentiment, and momentum," Journal of Financial and Quantitative Analysis, vol. 48, no. 1, pp. 245-275, 2013.

[4] L. Chi, X. Zhuang, and D. Song, "Investor sentiment in the Chinese stock market: an empirical analysis," Applied Economics Letters, vol. 19, no. 4, pp. 345-348, 2012.

[5] S. Akhtar, R. Faff, B. Oliver, and A. Subrahmanyam, "The power of bad: the negativity bias in Australian consumer sentiment announcements on stock returns," Journal of Banking \& Finance, vol. 35, no. 5, pp. 1239-1249, 2011.

[6] M. Schmeling, "Investor sentiment and stock returns: some international evidence," Journal of Empirical Finance, vol. 16, no. 3, pp. 394-408, 2009.

[7] P. C. Tetlock, "Giving content to investor sentiment: the role of media in the stock market," The Journal of Finance, vol. 62, no. 3, pp. 1139-1168, 2007.

[8] M. Baker and J. Wurgler, "Investor sentiment and the crosssection of stock returns," The Journal of Finance, vol. 61, no. 4, pp. 1645-1680, 2006.

[9] A. Kumar and C. M. C. Lee, "Retail investor sentiment and return comovements," The Journal of Finance, vol. 61, no. 5, pp. 2451-2486, 2006.

[10] W. Y. Lee, C. X. Jiang, and D. C. Indro, "Stock market volatility, excess returns, and the role of investor sentiment," Journal of Banking \& Finance, vol. 26, no. 12, pp. 2277-2299, 2002.

[11] K. L. Fisher and M. Statman, "Investor sentiment and stock returns," Financial Analysts Journal, vol. 56, no. 2, pp. 16-23, 2000.

[12] H. Hong and J. C. Stein, "A unified theory of underreaction, momentum trading, and overreaction in asset markets," The Journal of Finance, vol. 54, no. 6, pp. 2143-2184, 1999.

[13] R. J. Shiller, "Speculative prices and popular models," Journal of Economic Perspectives, vol. 4, no. 2, pp. 55-65, 1990.

[14] W. F. M. De Bondt and R. H. Thaler, "Further evidence on investor overreaction and stock market seasonality," The Journal of Finance, vol. 42, no. 3, pp. 557-581, 1987.

[15] R. J. Shiller, "Investor behavior in the october 1987 stock market crash: survey evidence," National Bureau of Economic Research Working Paper Series (w2446), 1987.

[16] S. A. Green and A. Ben-Sasson, "Anxiety disorders and sensory over-responsivity in children with autism spectrum disorders: is there a causal relationship?" Journal of Autism and Developmental Disorders, vol. 40, no. 12, pp. 1495-1504, 2010.

[17] R. A. Peterson and K. Plehn, "Measuring anxiety sensitivity," Anxiety Sensitivity: Theory, Research, and Treatment of the Fear of Anxiety, pp. 61-81, 1999.

[18] R. B. Malmo, "Studies of anxiety: some clinical origins of the activation concept," Anxiety and Behavior, Academic Press, Cambridge, MA, USA, pp. 157-177, 1966.

[19] N. Jegadeesh and S. Titman, "Returns to buying winners and selling losers: implications for stock market efficiency," The Journal of Finance, vol. 48, no. 1, pp. 65-91, 1993.

[20] W. F. M. De Bondt and R. Thaler, "Does the stock market overreact?” The Journal of Finance, vol. 40, no. 3, pp. 793-805, 1985. 
[21] E. Gilbert and K. Karahalios, "Widespread worry and the stock market," in Proceedings of the Fourth International AAAI Conference on Weblogs and Social Media, Washington, DC, USA, 2010, May.

[22] C. D. Spielberger, "State-trait anxiety inventory," The Corsini Encyclopedia of Psychology, p. 1, 2010.

[23] P. Ekman, "Emotions revealed," BMJ, vol. 328, no. 5, Article ID 0405184, 2004.

[24] B. B. Lahey, S. A. Schneider, R. E. Landrum, and T. Landrum, Psychology: An Introduction, Brown \& Benchmark Publishers, New York, NY, USA, 1995.

[25] W. K. Estes and B. F. Skinner, "Some quantitative properties of anxiety," Journal of Experimental Psychology, vol. 29, no. 5, pp. 390-400, 1941.

[26] D. G. Myers, Psychology: Myers in Modules, Worth Publishers, New York, NY, USA, 2001.

[27] R. L. Peterson, "Affect and financial decision-making: how neuroscience can inform market participants," Journal of Behavioral Finance, vol. 8, no. 2, pp. 70-78, 2007.

[28] M. W. Passer and R. E. Smith, Psychology: Frontiers and Applications, McGraw-Hill, Boston, MA, USA, 2000.

[29] B. Lauterbach and U. Ben-Zion, "Stock market crashes and the performance of circuit breakers: empirical evidence," The Journal of Finance, vol. 48, no. 5, pp. 1909-1925, 1993.

[30] A. Goyal and S. Wahal, "Is momentum an echo?" Journal of Financial and Quantitative Analysis, vol. 50, no. 6, pp. 1237-1267, 2015.

[31] A. Hillert, H. Jacobs, and S. Müller, "Media makes momentum," Review of Financial Studies, vol. 27, no. 12, pp. 3467-3501, 2014.

[32] C. S. Asness, T. J. Moskowitz, and L. H. Pedersen, "Value and momentum everywhere," The Journal of Finance, vol. 68, no. 3, pp. 929-985, 2013.

[33] S. Wahal and M. D. Yavuz, "Style investing, comovement and return predictability," Journal of Financial Economics, vol. 107, no. 1, pp. 136-154, 2013.

[34] J. Mossin, "Equilibrium in a capital asset market," Econometrica, vol. 34, no. 4, pp. 768-783, 1966.

[35] J. Lintner, "The valuation of risk assets and the selection of risky investments in stock portfolios and capital budgets," The Review of Economics and Statistics, vol. 47, no. 1, pp. 13-37, 1965.

[36] W. F. Sharpe, "Capital asset prices: a theory of market equilibrium under conditions of risk," The Journal of Finance, vol. 19, no. 3, pp. 425-442, 1964.

[37] E. F. Fama and K. R. French, "Common risk factors in the returns on stocks and bonds," Journal of Financial Economics, vol. 33, no. 1, pp. 3-56, 1993.

[38] J. Liu, R. F. Stambaugh, and Y. Yuan, "Size and value in China," Journal of Financial Economics, vol. 134, no. 1, pp. 48-69, 2019.

[39] Z. Chen and A. Lu, "Slow diffusion of information and price momentum in stocks: evidence from options markets," Journal of Banking \& Finance, vol. 75, pp. 98-108, 2017.

[40] G. G. Booth, H. G. Fung, and W. K. Leung, "A risk-return explanation of the momentum-reversal "anomaly"” Journal of Empirical Finance, vol. 35, pp. 68-77, 2016.

[41] R. D. McLean, "Idiosyncratic risk, long-term reversal, and momentum," Journal of Financial and Quantitative Analysis, vol. 45, no. 4, pp. 883-906, 2010.

[42] C. Wang and L. Xie, "Information diffusion and overreaction: evidence from the Chinese stock market," Emerging Markets Finance and Trade, vol. 46, no. 2, pp. 80-100, 2010.
[43] J. Kang, M.-H. Liu, and S. X. Ni, "Contrarian and momentum strategies in the China stock market: 1993-2000," Pacific-Basin Finance Journal, vol. 10, no. 3, pp. 243-265, 2002.

[44] Z. Gao, H. Ren, and B. Zhang, "Googling investor sentiment around the world," Journal of Financial and Quantitative Analysis, vol. 55, no. 2, pp. 549-580, 2016.

[45] G. Kaplanski and H. Levy, "Sentiment and stock prices: the case of aviation disasters," Journal of Financial Economics, vol. 95, no. 2, pp. 174-201, 2010.

[46] G. Boyle and B. Walter, "Reflected glory and failure: international sporting success and the stock market," Applied Financial Economics, vol. 13, no. 3, pp. 225-235, 2003.

[47] A. Fostel and J. Geanakoplos, "Leverage cycles and the anxious economy," American Economic Review, vol. 98, no. 4, pp. 1211-1244, 2008.

[48] M. J. Kamstra, L. A. Kramer, and M. D. Levi, "Losing sleep at the market: the daylight saving anomaly," American Economic Review, vol. 90, no. 4, pp. 1005-1011, 2000.

[49] O. Levy and I. Galili, "Stock purchase and the weather: individual differences," Journal of Economic Behavior \& Organization, vol. 67, no. 3-4, pp. 755-767, 2008.

[50] H.-H. Huang, M.-L. Chan, I.-H. Huang, and C.-H. Chang, "Stock price volatility and overreaction in a political crisis: the effects of corporate governance and performance," PacificBasin Finance Journal, vol. 19, no. 1, pp. 1-20, 2011.

[51] J. R. Nofsinger, "Social mood and financial economics," Journal of Behavioral Finance, vol. 6, no. 3, pp. 144-160, 2005.

[52] G. Barlevy and P. Veronesi, "Rational panics and stock market crashes," Journal of Economic Theory, vol. 110, no. 2, pp. 234-263, 2003.

[53] D. Coon and J. O. Mitterer, Introduction to Psychology: Gateways to Mind and Behavior with Concept Maps and Reviews, Cengage Learning, Boston, MA, USA, 2012.

[54] C. Peterson, Psychology: A Biopsychosocial Approach, Longman, New York, NY, USA, 1997.

[55] J. L. Valls, Freudian Dictionary: A Comprehensive Guide to Freudian Concepts, Routledge, London, UK, 2019.

[56] J. Webster, Conversion Disorder: Listening to the Body in Psychoanalysis, Columbia University Press, New York, NY, USA, 2018.

[57] B. B. Wolman, Logic of Science in Psychoanalysis, Columbia University Press, New York, NY, USA, 1984.

[58] Z. Da, U. G. Gurun, and M. Warachka, "Frog in the pan: continuous information and momentum," Review of Financial Studies, vol. 27, no. 7, pp. 2171-2218, 2014.

[59] B. Kim and S. Suh, "Sentiment-based momentum strategy," International Review of Financial Analysis, vol. 58, pp. 52-68, 2018.

[60] L. Menkhoff, L. Sarno, M. Schmeling, and A. Schrimpf, "Currency momentum strategies," Journal of Financial Economics, vol. 106, no. 3, pp. 660-684, 2012.

[61] R. Novy-Marx, "Is momentum really momentum?" Journal of Financial Economics, vol. 103, no. 3, pp. 429-453, 2012.

[62] U. Celiker, N. V. Kayacetin, R. Kumar, and G. Sonaer, "Cash flow news, discount rate news, and momentum," Journal of Banking \& Finance, vol. 72, pp. 240-254, 2016.

[63] Y. Chen and H. Zhao, "Informed trading, information uncertainty, and price momentum," Journal of Banking \& Finance, vol. 36, no. 7, pp. 2095-2109, 2012.

[64] L. Garlappi and H. Yan, "Financial distress and the crosssection of equity returns," The Journal of Finance, vol. 66, no. 3, pp. 789-822, 2011.

[65] D. C. Montgomery, Design and Analysis of Experiments, John Wiley \& Sons, Hoboken, NJ, USA, 2017. 
[66] M. Verardo, "Heterogeneous beliefs and momentum profits," Journal of Financial and Quantitative Analysis, vol. 44, no. 4, pp. 795-822, 2009.

[67] D. Avramov, T. Chordia, G. Jostova, and A. Philipov, "Momentum and credit rating," The Journal of Finance, vol. 62, no. 5, pp. 2503-2520, 2007.

[68] H. White, "A heteroskedasticity-consistent covariance matrix estimator and a direct test for heteroskedasticity," Econometrica, vol. 48, no. 4, pp. 817-838, 1980.

[69] M. Schaub, "Investor overreaction to going concern audit opinion announcements," Applied Financial Economics, vol. 16, no. 16, pp. 1163-1170, 2006.

[70] B. Hayo and A. M. Kutan, "IMF-related news and emerging financial markets," Journal of International Money and Finance, vol. 24, no. 7, pp. 1126-1142, 2005.

[71] A. Kutan and B. Sudjana, "Investor reaction to IMF actions in the Indonesian financial crisis," The Journal of Policy Reform, vol. 6, no. 3, pp. 181-190, 2003.

[72] R. P. Chang, K.-C. Ko, S. Nakano, and S. Ghon Rhee, "Residual momentum in Japan," Journal of Empirical Finance, vol. 45, pp. 283-299, 2018. 